\title{
Off-design performance modelling of a Solar Organic Rankine Cycle integrated with pressurized hot water storage unit for community level application
}

\author{
Cagri Kutlu ${ }^{1}$, Jing $\mathrm{Li}^{1,2, *}$, Yuehong $\mathrm{Su}^{1 * *}$, Gang Pei $^{2}$, Saffa Riffat ${ }^{1}$ \\ ${ }^{I}$ Department of Architecture and Built Environment, Faculty of Engineering, University of \\ Nottingham, University Park, Nottingham NG7 2RD, UK \\ ${ }^{2}$ Department of Thermal Science and Energy Engineering, University of Science and Technology of \\ China, 96 Jinzhai Road, Hefei, China
}

\begin{abstract}
Solar organic Rankine cycle (ORC) has advantages over common PV systems in view of the flexible operation even if solar radiation is unavailable. However, at present the dynamic performance of solar ORC with respect to the off-design behaviour of storage unit, expander, pump and heat exchanger is rarely reported. This paper investigates a medium-temperature solar ORC system characterized by evacuated flat-plate collectors and pressurised water storage unit. The main aim of the study is to investigate the performance of the system with consideration of transient behaviour of the thermal storage unit which results in off-design operation of other components. The other aim is adjusting the power output according to electricity demand throughout a day. The heat storage unit is analysed using one-dimensional temperature distribution model. A transient simulation model is developed including pump and expander models. To meet the electrical demands of different periods, the mass flow rate of heat source is adjusted for controlling the evaporation temperature. Moreover, sliding pressure operation control strategy of the ORC is implemented to meet variable heat source temperature. A $550 \mathrm{~m}^{2}$ solar collector area and a 4 meters diameter and 7 meters height pressurized water cylinder are used in simulation. Produced work is controlled and the results are matched with the demands. Produced work from the expander under the given conditions are $47.11 \mathrm{kWh}$ in day time, $70.97 \mathrm{kWh}$ in peak period and $31.59 \mathrm{kWh}$ after midnight.
\end{abstract}

*First corresponding author. Jing Li, ezzj13@exmail.nottingham.ac.uk

** Second corresponding author. Yuehong Su, yuehong.su@ nottingham.ac.uk 


\section{Introduction}

37 Renewable energy technologies have received specific worldwide attention, especially in developed countries. Although fossil fuels will undoubtedly remain the most dominant energy source over the next decades, special attention must be given to the provision of cleaner, more secure and sustainable energy sources, as strongly supported by public opinion. This trend has established renewable technologies as a necessary participant in energy production with an exponential growth in recent years in this sector. Solar energy has been defined as one of the most promising type of renewable energy sources. Solar-based energy systems are not only used for electricity generation but also applicable in various energy demanding systems such as refrigeration, desalination, hydrogen production and improvement of indoor environmental conditions [1].

In most parts of the world, electricity is the most important, sought after energy source for residential consumers. Electricity can be easily converted to other energies and household appliances need it in order to work. These factors make electricity the most demanded energy. Electricity suppliers provide the demand but their supply is not stable during the day. Previous studies have been conducted to specify and model the hourly demands [2],[3]. The magnitude of this demand may differ from country to country but the general trend is quite similar for all houses [4],[5]. Fig. 1 shows as an example of the $24 \mathrm{~h}$ domestic electricity demand of a dwelling in the UK [6]. To find a sustainable solution, PV cells have been used for years and expected to have a significant share in the upcoming electric generation systems [7]. However, as it is nature, electricity generation is intermitted with environmental factors and it needs solar irradiance absolutely. As seen from Fig. 1, peak demand occurs in the evening when there is no or significantly less residual solar irradiance. As a solution, the electricity can be stored in Lithium batteries but these come at a substantial cost and difficulty in quantifying its operational benefits for the grid [6],[8]. Therefore, storing the heat in a medium which is collected by solar collectors, then using it as a heat source for the ORC is appropriate given that ORC technology has in recent years become a promising technology for converting heat into electricity [9]. 


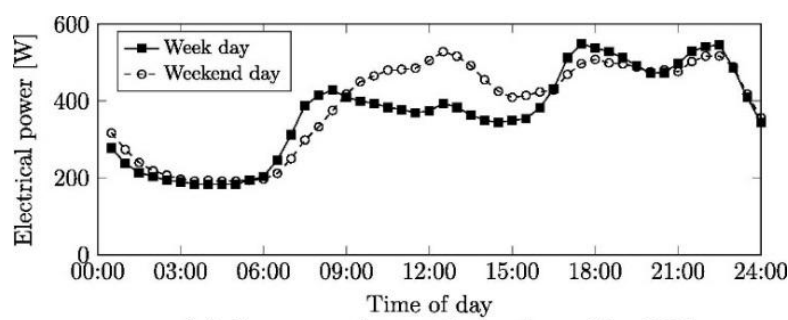

(a) Summer domestic load profile, UK.

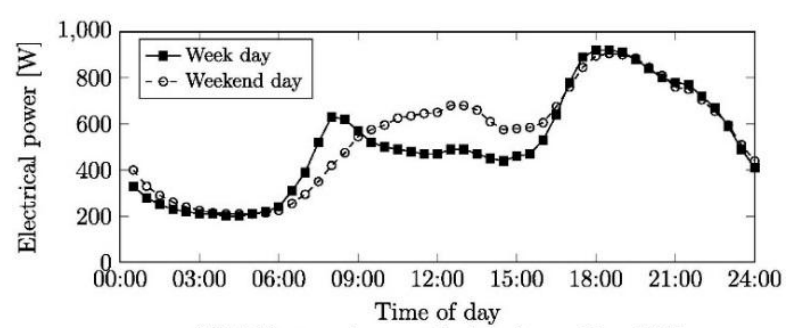

(b) Winter domestic load profile, UK.

Fig. 1. Domestic load profile in UK [6]

Many works have been done on solar ORC, generally parabolic through collectors have been preferred: Wang et al. [10] examined the off-design behaviour of the solar ORC under variation of the environment temperature and thermal oil mass flow rates of vapour generator. They concluded lower environment temperature could improve the performance. Chacartegui et al. [11] analysed a 5MW parabolic trough plant with ORC power block and thermal storage. They presented off-design and cost analysis and findings indicate that the investment cost for direct thermal energy storage systems is a $17 \%$ lower than the investment cost for indirect storage system. Tzivanidis et al. [12] conducted a parametric analysis of a solar ORC plant by using parabolic trough collectors to be optimize the system according to energy and financial considerations. Their results suggest that increasing the total collecting area reduces the solar thermal efficiency. Also flat plate collectors have been used in solar ORC systems. Wang et al. [13] prepared an experimental rig to compare two collector types and they found overall power generation efficiency was $4.2 \%$ for evacuated solar collectors and about $3.2 \%$ for flat plate solar collectors. Wang et al. [14] studied a solar-driven regenerative solar ORC with flat plate collector to compare working fluids. Their results show that R245fa and R123 are the most suitable working fluids due to higher system performance at low operation pressure. Freeman et al. [6] examined an integrated thermal energy storage for a domesticscale solar combined heat and power system to match to the end-user demands by using evacuated flat plate collectors. They concluded that Phase Change Materials for latent thermal-energy storage were shown to provide a greater power-output from the system for a smaller equivalent storage volume than water. 
Studies on the dynamic performance of solar ORC system are rare but in a fast rising trend [15],[16],[17]. However, transient performance of solar ORC in comprehensive consideration of the off-design behaviour of thermal storage unit, expander, pump and heat exchangers has not been reported yet. It is still needed to clarify how flexible a solar ORC system can operate and how it can fulfil the consumers' peak demand.

The objective of this paper is to provide a comprehensive model of the off-design analysis based on fulfilment of end user demand during the day by controlling the operation parameters. Several sub-models are included in the analysis:

- The ORC is modelled with consideration of the expander and pump behaviour alongside variations in operating conditions, such as isentropic efficiencies and working fluid mass flow rate.

- Sliding pressure operation strategy is implemented to allow and control the electricity production under varying heat source temperature.

- Transient heat storage unit is modelled with considering the thermocline behaviour. It is analysed using a one-dimensional temperature distribution model.

- To satisfy the electricity demand and conserve the heat in the storage, mass flow rate of water is controlled at different periods. Therefore, the system operates and is analysed at off-design conditions.

\section{System description}

The examined system in this study is shown in Fig. 2. The system is comprised of three subsystems, namely, the collectors, water storage tank and ORC block. The collectors, storage medium and expander were carefully selected on the following basis:

Evacuated flat plate collectors are chosen for heat collection. Using evacuated flat plate collectors has advantages over other types of collectors, for example, parabolic trough collectors in power generation plants. They do not need a sun tracking system and evacuated types can be used not only in countries where direct beam is available, but also on a grand scale. Their performance is quite good even under the conditions of low radiation and low ambient temperature compared to conventional flat plate collectors so there is a potential for use in winter. Therefore, evacuated type collectors are a good candidate for the power generation plants with a storage unit. 
In large scale solar thermal electricity generation systems, there are many alternative materials for thermal storage, namely, molten salts, thermal oils and water. It is suggested that molten salt is the best choice for thermal storage in high temperature operations $\left(>400^{\circ} \mathrm{C}\right)$ [18]. Thermal oil is also promising in the temperature range between $300^{\circ} \mathrm{C}$ and $400^{\circ} \mathrm{C}$, for lower operating temperature, water can be properly used because water has good thermal properties and has a much lower cost compared to other fluids [19]. In the present study, the temperature range of the operation which is below $150{ }^{\circ} \mathrm{C}$ makes water a proper storage media. The working fluid which is pressurized water remains in liquid phase in all cases while operating with 5 bar pressure [20].

Working fluid in the ORC plays an important role because it is related to thermal performance and economics of the power plant. A number of researchers studied the effect of the working fluid selection on system performance [21],[22]. R245fa is a very common and effective working fluid for low temperature solar systems according to some theoretical analyses. Its performance has been investigated especially in small scale systems with commonly using a scroll expander [9],[23], [24].

The scroll type expander was selected as an expansion device in the present study because it is particularly well adapted to small-scale Rankine cycle applications that are lower than 25 kWe power output. Also, it offers major advantages such as low rotational speeds, reliability and robustness (less number of moving parts), and the ability to handle high pressure ratio [25].

Fig. 2 illustrates the examined system. High performance evacuated flat-plate collectors are used for heating the water which comes from the bottom of the tank $\left(\mathrm{T}_{\mathrm{st1} 10}\right)$ by converting solar radiation to heat and filling the tank to the topside $\left(\mathrm{T}_{\mathrm{col}}\right)$. In Section 4.1, the equations and specifications of collectors are given. Water is used as the heat transfer fluid instead of thermal oil because of its more favourable thermal properties and its ability to be directly discharged into the tank without heat exchangers. The water storage tank has two inlet and two outlet; usage of these ports depends on the working periods, the analysis and related equations as given in Section 4.2. Lastly, the ORC block working principle is clarified in Section 4.3. 

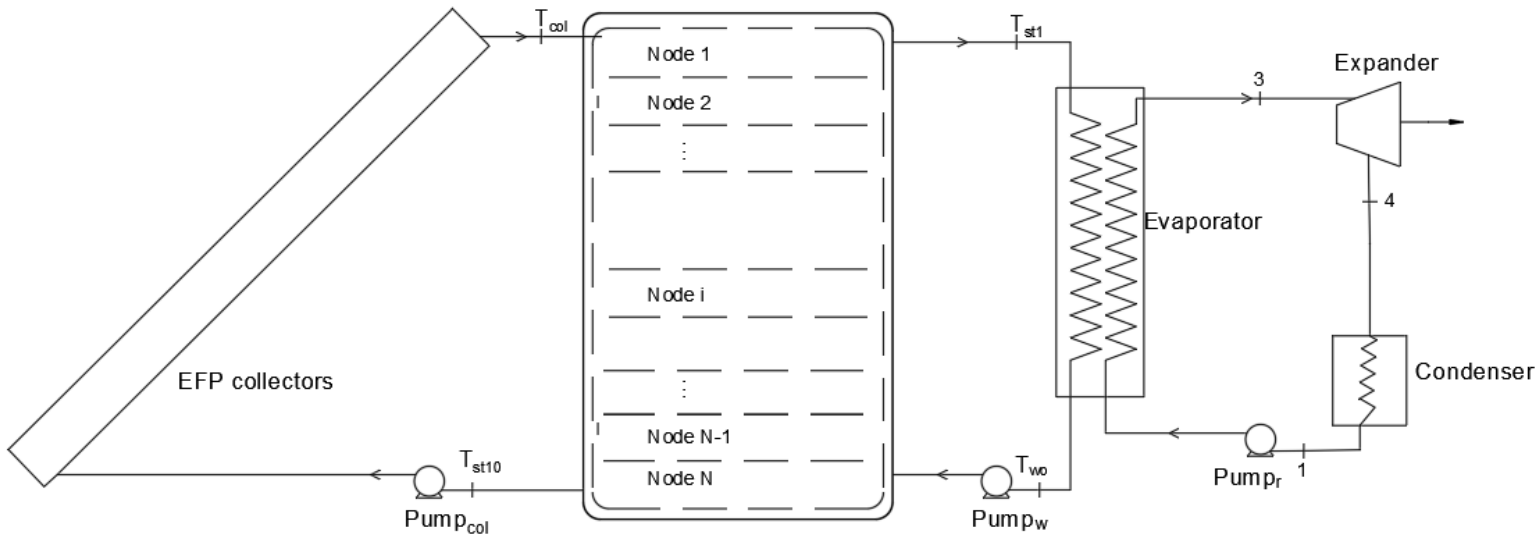

Fig. 2. Schematic view of the system

\section{Methodology}

The examined system in this study should provide the required average electricity needed for an average house in a small community. According to the reference [6], 24h of a day are divided into three different time periods in the present study, as shown in Fig. 3. By including the electricity generator efficiency, the approximate required work outputs per house should be minimum $0.5 \mathrm{~kW}$ for the day time, $0.75 \mathrm{~kW}$ for the early night and $0.3 \mathrm{~kW}$ for the late night period. The peak energy demand is observed in the early night period so the design conditions of the system are selected by considering the higher electricity demand. The relevant explanations will be given in Section 5.1.

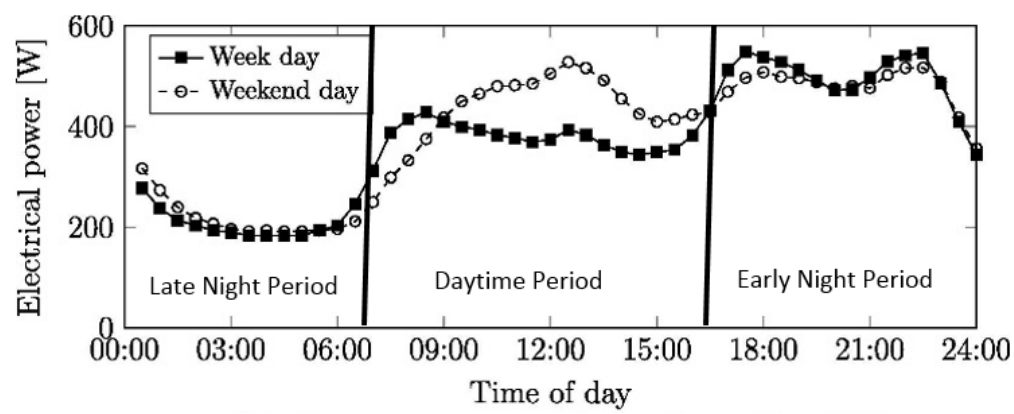

Fig. 3. Three periods in a day [6]

In this paper, firstly the ORC working conditions will be determined using design parameters subjected to performance characteristics of the expander [26]. Condensing temperature can be 
found by ambient temperature but evaporating temperature depends completely on heat source temperature, so analysis should be conducted with heat source temperature which is not constant during the day (charging and discharging). The effect of variation of heat source temperature requires some control methods in the model, as the ORC alone cannot prevent the unstable trend. According to conventional Rankine cycles, there are two types of operating control strategies suggested in the literature, namely, constant pressure and sliding pressure operations. Hu et al. [27] explained and compared the control strategies in their paper. Fu et al. [28] investigated the effect of heat source temperature on the system performance by using sliding pressure operation strategy. They considered economizer performance which only includes single phase heat transfer. However, in the present study, the evaporator is also taken into consideration to determine evaporating temperature of the ORC.

Fig. 4 shows the outline of the processes in this paper. A general methodology of the analysis of off-design performance is implemented [29]. As a first step, the ORC is designed for ondesign conditions. Since the most critical and higher electricity requiring period is at early night, design of the heat exchangers will be conducted according to this period. Then offdesign performance will be investigated for other periods by using previously dimensioned heat exchangers. Lastly, parametric study will be conducted to determine proper water storage tank size and number of collectors.

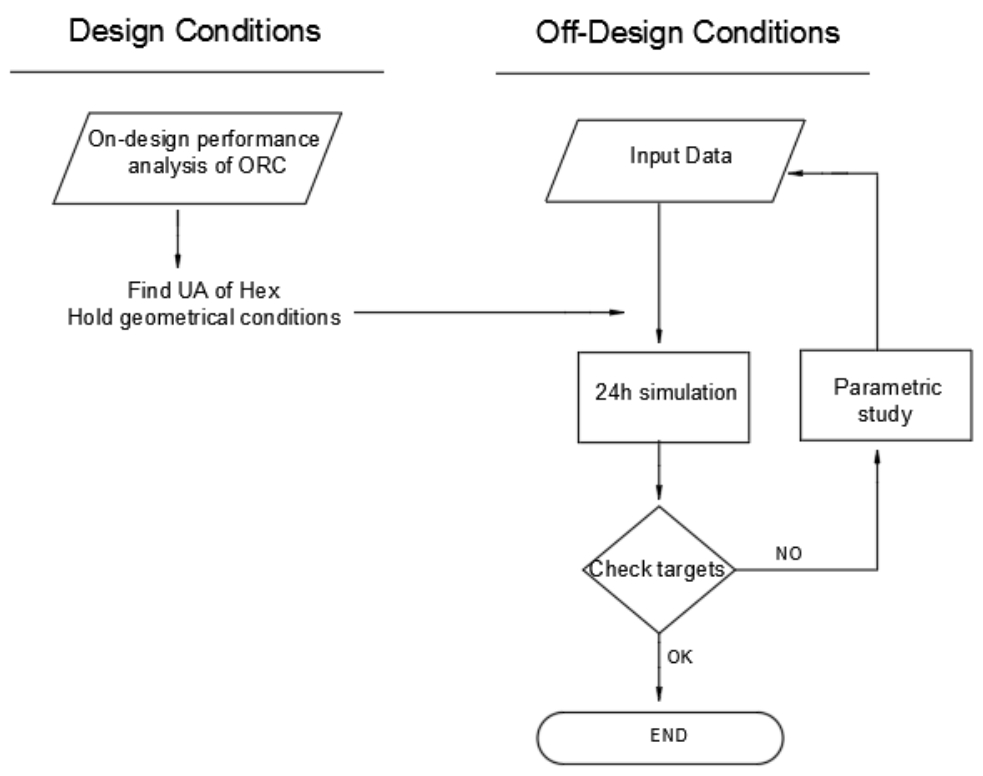




\section{Mathematical modelling}

\subsection{Solar collector modelling}

189

190

191

192

193

196

197

201

202

203

204

205

206

207

The solar collector chosen for this study is the TVP SOLAR HT-Power, high efficiency evacuated flat plate collector, already evaluated for its potential in ORC systems by Freeman et.al [6], [22] and Calise et.al [30]. In the aforementioned studies diathermic oil was used as a working fluid, however, in this study pressurized water is used as a heat transfer fluid for reasons explained in previous sections. Modelling of the evacuated flat-plate collector follows the same assumptions as in the reference [22], so the efficiency of the solar collector can be given by:

$$
\eta_{c}=\eta_{0} \cdot K_{\theta}-c_{1} \frac{\bar{T}-T_{a m}}{G}-c_{2} \frac{\left(\bar{T}-T_{a m}\right)^{2}}{G}
$$

Where the collector parameters are taken from [30] which are $\eta_{0}=0.82, K_{\theta}=0.91, c_{1}=0.399$, $c_{2}=0.0067 . \eta_{0}$ is solar collector zero-loss efficiency, $K_{\theta}$ is incident angle modifier, $c_{1}$ and $c_{2}$ are collector heat loss coefficients. The quantity of solar radiation absorbed by the collector array is equal to the enthalpy increase of the working fluid:

$$
\dot{Q}_{c o l}=\eta_{c o l} \cdot A_{c o l} \cdot G=\dot{m}_{c w} \cdot c_{p c w} \cdot\left(T_{c o l}-T_{s t N}\right)
$$

Where $t_{c o l}$ and $t_{s t N}$ indicate the collector outlet water temperature and water return temperature from the tank, respectively.

\subsection{Water storage tank modelling}

Solar collectors are coupled with the water storage tank and its modelling is described in this section. One of the important components in the system is the water storage tank because it is used as the heat source for the ORC. Its energy capacity, which is related to its volume, determines the energy storage level in the system and affects the temperature gradient of the tank. A number of studies have investigated the thermal stratification in water storage tanks and have analysed from 1D to 3D models [31]. Generally, 1D models have used experimentally or CFD based correction factors. So in the present study, as the most 


$$
\begin{aligned}
M_{s t N} \cdot c_{p w} \cdot \frac{\partial T_{s t N}}{\partial t} & \\
& =\dot{m}_{c w} \cdot c_{p c w} \cdot\left(T_{s t(N-1)}-T_{s t N}\right)+\dot{m}_{w} \cdot c_{p w} \cdot\left(T_{w o}-T_{s t N}\right)-U_{t} \cdot A_{s t N} \\
& \cdot\left(T_{s t N}-T_{a m}\right)
\end{aligned}
$$

225 Where $\dot{m}_{c w}$ and $\dot{m}_{w}$ indicate water mass flowrate coming from collector and evaporator 226 respectively. $T_{w o}$ is the water temperature coming from the evaporator to the tank bottom node. $U_{t}$ indicates the thermal loss coefficient of the well-insulated tank as $0.8 \mathrm{~W} \mathrm{~m}^{-2} \mathrm{~K}^{-1}$ [35]. The tank has a cylindrical shape with diameter $d_{s t}$ and height $L$, and the outer areas of nodes are given in equations as below:

$$
\begin{gathered}
A_{s t 1}=\frac{\pi d_{s t}{ }^{2}}{4}+\frac{\pi d_{s t} L}{N} \\
A_{s t(i)}=\frac{\pi d_{s t} L}{N}
\end{gathered}
$$


and the last node:

$$
A_{s t N}=\frac{\pi d_{s t}^{2}}{4}+\frac{\pi d_{s t} L}{N}
$$

231 The static mode of the storage tank means there are no external forced flows entering or leaving the tank. Therefore, conduction heat transfer between the nodes should be considered. Heat loss to the environment also creates thermal stratification in the tank, as fluids near the wall are cooled due to heat loss and these lower temperature fluids, which have lower density, go through the bottom of the tank. This phenomenon has been previously studied by other researchers [36], [37]. Armstrong et.al [38] investigated the influence of the wall material specification on de-stratification and showed that thermal conduction of the wall material has a strong influence on this. Cruickshank et.al [37] formulated the energy balance equation when there are no flows entering or exiting the tank:

240

$$
\begin{aligned}
M_{s t(i)} \cdot c_{p w} \cdot \frac{\partial T_{s t(i)}}{\partial t} & \\
& =\frac{(k+\Delta k) A_{c(i)}}{\Delta x_{i+1 \rightarrow i}} \cdot\left(T_{s t(i+1)}-T_{s t(i)}\right)+\frac{(k+\Delta k) A_{c(i)}}{\Delta x_{i-1 \rightarrow i}} \cdot T_{s t(i-1)}-T_{s t(i)}-U_{t} \cdot A_{s t(i)} \\
& \cdot\left(T_{s t(i)}-T_{a m}\right)
\end{aligned}
$$

Where $\Delta x_{i+1 \rightarrow i}$ and $\Delta x_{i-1 \rightarrow i}$ are a center-to-center distance between nodes, $k$ and $\Delta k$ are the thermal conductivity of water and the de-stratification conductivity. Newton [39] derived empirically of this conduction term $\Delta k$ using tank wall lateral area $A_{\text {lwall }}$ :

$$
\Delta k=k_{w a l l}+\frac{A_{l w a l l}}{A_{c(i)}}
$$

\subsection{Organic Rankine cycle}

The organic Rankine cycle (ORC) mainly consists of refrigerant pump, evaporator, expander and condenser. The system schematic can be seen in Fig. 2. The refrigerant enters the pump as a saturated liquid ' 1 ' at condensing pressure, then its pressure is increased by pump to the 
evaporating pressure level ' 2 '. Evaporating pressure depends on the heat source temperature and the ORC working strategy which will be explained in Section 4.4. Next component of the ORC is evaporator where the heat is supplied from the water storage, at the outlet of the evaporator, the fluid phase is saturated vapour ' 3 '. Then it goes into the expander. The expander produces work and decreases fluid pressure to condensing pressure and finally, the refrigerant enters the condenser at point ' 4 '. To indicate the state points, a T-s diagram of the ORC cycle is given in Fig. 5. In following subsections, every component of the ORC is modelled to simulate system with varying conditions.

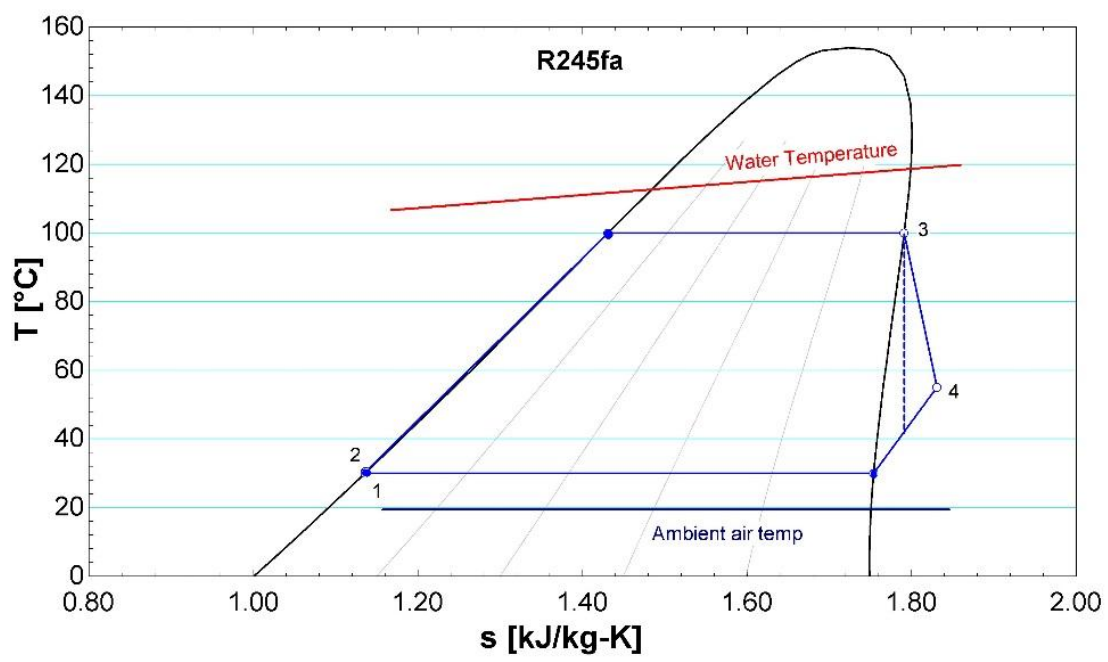

Fig. 5. T-s diagram of ORC

\subsubsection{ORC pump modelling}

The pump isentropic efficiency is not constant as the discharge pressure and mass flow rate vary with evaporation temperature. Quoilin et al [40] have used some empirical equations for modelling their dynamic ORC system. The same equations are followed, so the isentropic pump efficiency is defined as Eq. (11) and the pump empirical equation is Eq. (12)

$$
\eta_{\text {pump }}=\frac{h_{2 s}-h_{1}}{h_{2}-h_{1}}
$$

$$
\eta_{\text {pump }}=a_{0}+a_{1} \cdot \log \left(X_{p}\right)+a_{2} \log \left(X_{p}\right)^{2}+a_{3} \log \left(X_{p}\right)^{3}
$$

$X_{p}$ is the pump capacity fraction, which is given by: 


$$
X_{p}=\frac{\vartheta_{s u} \cdot \dot{m}_{r}}{\dot{V}_{s u, p, \max }}
$$

269

270

271 The relevant parameters in Eqs. (12), (13) and (14) are listed in Table 1.

272 Table 1. Pump model parameters

\begin{tabular}{|cccc|}
\hline$\dot{\mathrm{V}}_{\text {su,p,max }}$ & $0.25 \mathrm{l} / \mathrm{s}$ & $\eta_{\mathrm{me}, \mathrm{p}}$ & 0.9 \\
$\mathrm{a}_{0}$ & 0.93 & $\mathrm{a}_{1}$ & -0.11 \\
$\mathrm{a}_{2}$ & -0.2 & $\mathrm{a}_{3}$ & -0.06 \\
\hline
\end{tabular}

273

The overall pump efficiency is therefore:

$$
\eta_{\text {overall }}=\eta_{m e, p} \cdot \eta_{\text {pump }}
$$

$$
3
$$

74

\subsubsection{Expander modelling}

The expander is the most critical component in low-capacity ORC systems. In this study, a scroll type expander was decided to use. According to the literature search, there are some models are available from several applications. An air scroll expander is selected and empirical equations taken from ref. [23] were used. In selected study, empirical equations depend on three parameters: inlet pressure of the expander, pressure ratio and rotational speed. To obtain a generic non-dimensional performance curve of the expander, input variables were carefully selected by the authors, and only ambient heat losses were disregarded. According to the expander model, isentropic efficiency and filling factor are defined in Eq. (15) and Eq. (16).

$$
\eta_{\text {exp }}=\frac{\dot{W}_{\text {shaft }}}{\dot{m}_{r}\left(h_{s u}-h_{e x, s}\right)}
$$

$$
\phi=\frac{\dot{m}_{r} v_{s u}}{\dot{V}_{s}}
$$




$$
\begin{gathered}
\eta_{\text {exp }}=y_{\text {max }} \cdot \sin \left(\xi \cdot \arctan \left(B \cdot\left(r_{p}-r_{p, 0}\right)-E \cdot\left(B \cdot\left(r_{p}-r_{p, 0}\right)-\arctan \left(B \cdot\left(r_{p}-r_{p, 0}\right)\right)\right)\right)\right) \\
\phi=\phi_{n}-b_{0} \cdot \ln \left(\frac{N_{r o t}}{3000}\right)+b_{1} \cdot r_{p}^{*}+b_{2} \cdot p^{*} \\
B=\frac{\delta}{\xi y_{\max }} \\
E=\frac{B \cdot\left(r_{p}-r_{p, 0}\right)-\tan \left(\frac{\pi}{2 \xi}\right)}{B \cdot\left(r_{p}-r_{p, 0}\right)-\arctan \left(B \cdot\left(r_{p}-r_{p, 0}\right)\right)}
\end{gathered}
$$

289 Where each of the parameters can be expressed as a polynomial function of the nondimensional rotational speed and pressure [41]. Explanations of the parameters and constants and derivation of equations can be taken from the given ref. [23]. Fig. 6 gives the expander efficiency variation with pressure ratio for the given conditions. It is seen that pressure ratio between the expander inlet and outlet has an influence on expander isentropic efficiency. The condensing pressure or temperature is related with the ambient temperature so environmental changes also affect the system performance. However, in this study, it is taken as constant condensing temperature at $30^{\circ} \mathrm{C}$, which will be explained in Section 5.1. Expander performance depends on the evaporating pressure which is related with the temperature of heat source. In order to obtain higher performance from the expander, the evaporating temperature is controlled between $80^{\circ} \mathrm{C}$ and $100^{\circ} \mathrm{C}$. The expected working range of the expander under given conditions is also shown in Fig. 6.

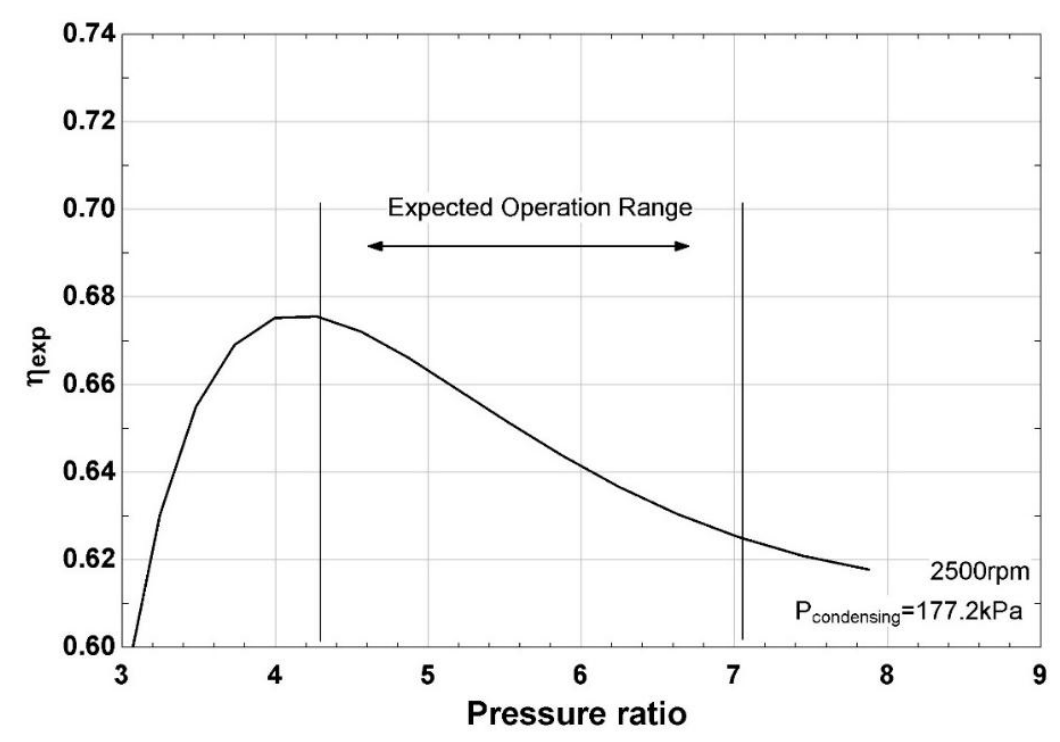




\subsection{Heat exchanger modelling and control strategy}

307 In the ORC block, two heat exchangers are used for different purposes. For neglecting 308 pressure losses and making the study more practical, double pipe heat exchangers are selected 309 for this study, as chosen by various other authors [40], [42], [43] for the same reasons. To 310 find the effectiveness of the heat exchangers, the effectiveness-NTU method was implemented in the analysis. Some equations are used [44],[45],[46] to find heat transfer coefficients for single and two phase states in the literature. This study uses Gnielinski equation where the fluids exist in a single state (liquid water, pure liquid and pure vapor R245fa), as given in Eqs. (21) and (22), which are used and defined in Ref.[47] for turbulent flow.

$$
\begin{gathered}
h=\frac{\left(\frac{f}{8}\right)(\operatorname{Re}-1000) \operatorname{Pr}}{1+12.7\left(\frac{f}{8}\right)^{0.2}\left(\operatorname{Pr}^{2 / 3}-1\right)}\left(\frac{k}{d}\right) \\
f=(0.79 \ln R e-1.64)^{-2}
\end{gathered}
$$

317 When boiling of the refrigerant R245fa takes place, fluid is in two-phase state (saturated 318 mixture). For boiling in the evaporator, the Kenning-Cooper correlation in Eq. (23) is used as 319 given by Sun and Mishima [48] based on their findings.

$$
h_{b}=\left[1+1.8 X^{-0.87}\right] 0.023 \operatorname{Re}_{l}^{0.8} \operatorname{Pr}_{l}^{0.48}(k / d)
$$

320

321 Where $\mathrm{X}$ is the Martinelli factor which is given from vapour quality $\mathrm{x}$ :

$$
X=\left(\frac{1-x}{x}\right)^{0.9}\left(\frac{\rho_{v}}{\rho_{l}}\right)^{0.5}\left(\frac{\mu_{l}}{\mu_{v}}\right)^{0.1}
$$


The most important heat exchanger unit in the ORC block is the evaporator. The pressure control strategy is closely related to adjusting the evaporation temperature. The evaporator includes two regions in one exchanger such as single phase and evaporating regions. The refrigerant temperature is increased to the desired level in the single phase region and then the phase is changed into saturated vapour in the evaporating region. A schematic view of the evaporator is given in Fig. 7. In off-design operation, total length of the evaporator has to be constant but regions may differ according to heat source conditions. The evaporator uses hot water flow from the heat storage tank as a heat source. This means the source temperature cannot stand constant because the storage tank temperature will fall during the operation period. To calculate the evaporating temperature when heat source temperature varies, the sliding pressure control method is used in analyses.

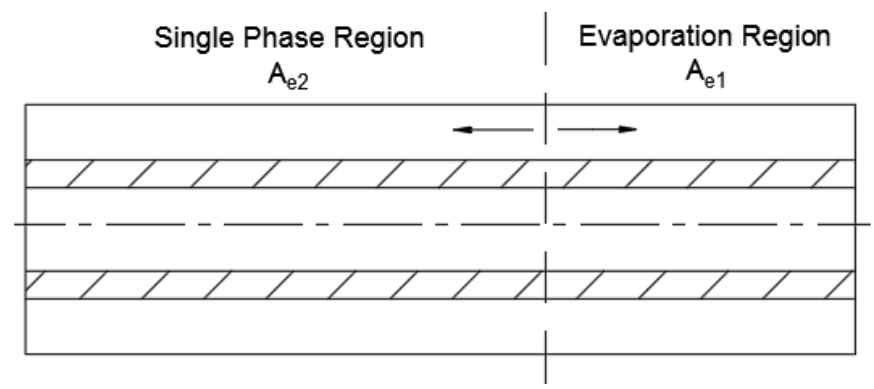

Fig. 7. Schematic of evaporator single and two-phase regions boundary

The T-s diagram related with variable evaporation temperature is given in Fig. 8. Variation of evaporation temperature results with variable work output of the expander. It also effects the rejected heat from the heat source so it will be used in analysis to get balanced energy conversion with providing energy demands. Once the dimensions of the evaporator are determined according to design conditions, sliding pressure control procedure is applied to find the evaporating temperature in off-design conditions. This control strategy follows; area of the evaporating region and evaporating temperature are assumed by the user. The heat transfer coefficients are found according to given conditions then the effectiveness-NTU method is applied into the evaporating region until a proper evaporating temperature is found. Proper temperature is found by comparing the assumed parameters' effectiveness and new effectiveness. Difference between assumed and calculated values is continues to iteration until difference would be smaller than a certain value. After satisfying the evaporating side, the area of the single phase region is found. The same procedure is followed and if the state is 
not convincing the loop returns to beginning and the area of the evaporation region is altered.

351 The related flow chart showing the procedure is given in Fig. 9.

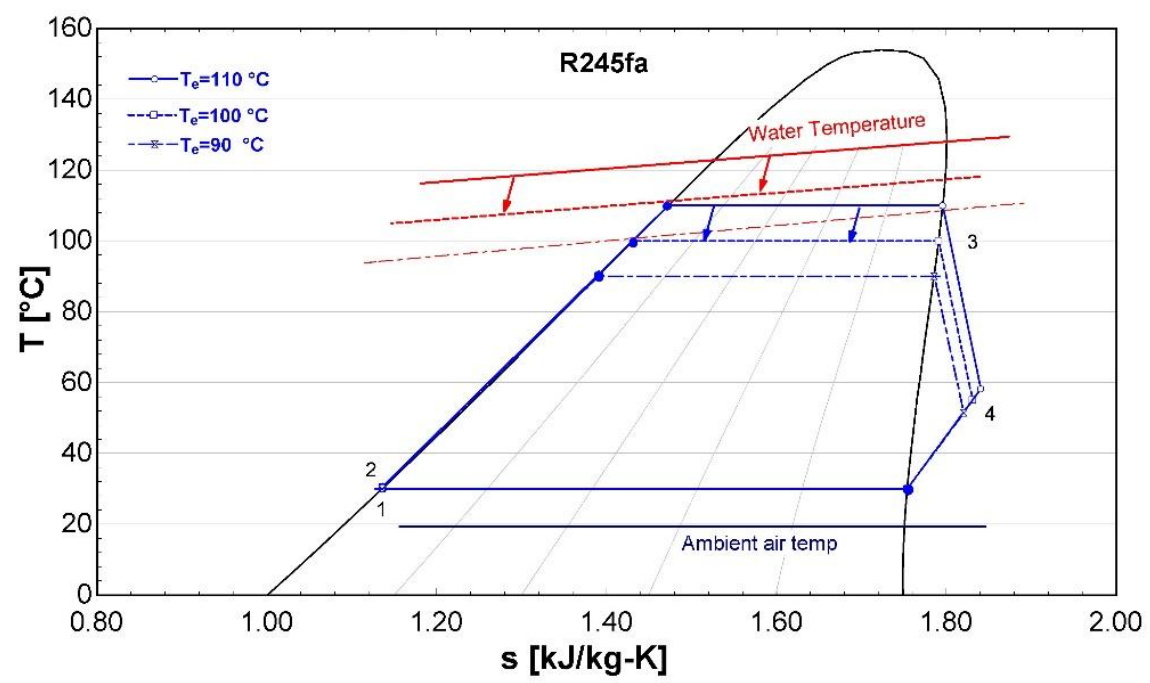

Fig. 8. Sliding pressure operation

356 The other heat exchanger device in the ORC block is condenser. It is used for rejecting heat 357 from refrigerant to the environment; water or air cooled condensers are available in the 358 literature but in this study the air cooled condenser was used because small scale solar cogeneration system condensing loads are not at high levels, and also using the air cooled condenser is more practical. The heat load of the condenser depends on the inlet condition of

361 the refrigerant it also depends on evaporating temperature, expander efficiency. However, 362 performance investigation of the condenser is not within the scope of this study because heat load can be easily adjustable by fan speeds. 


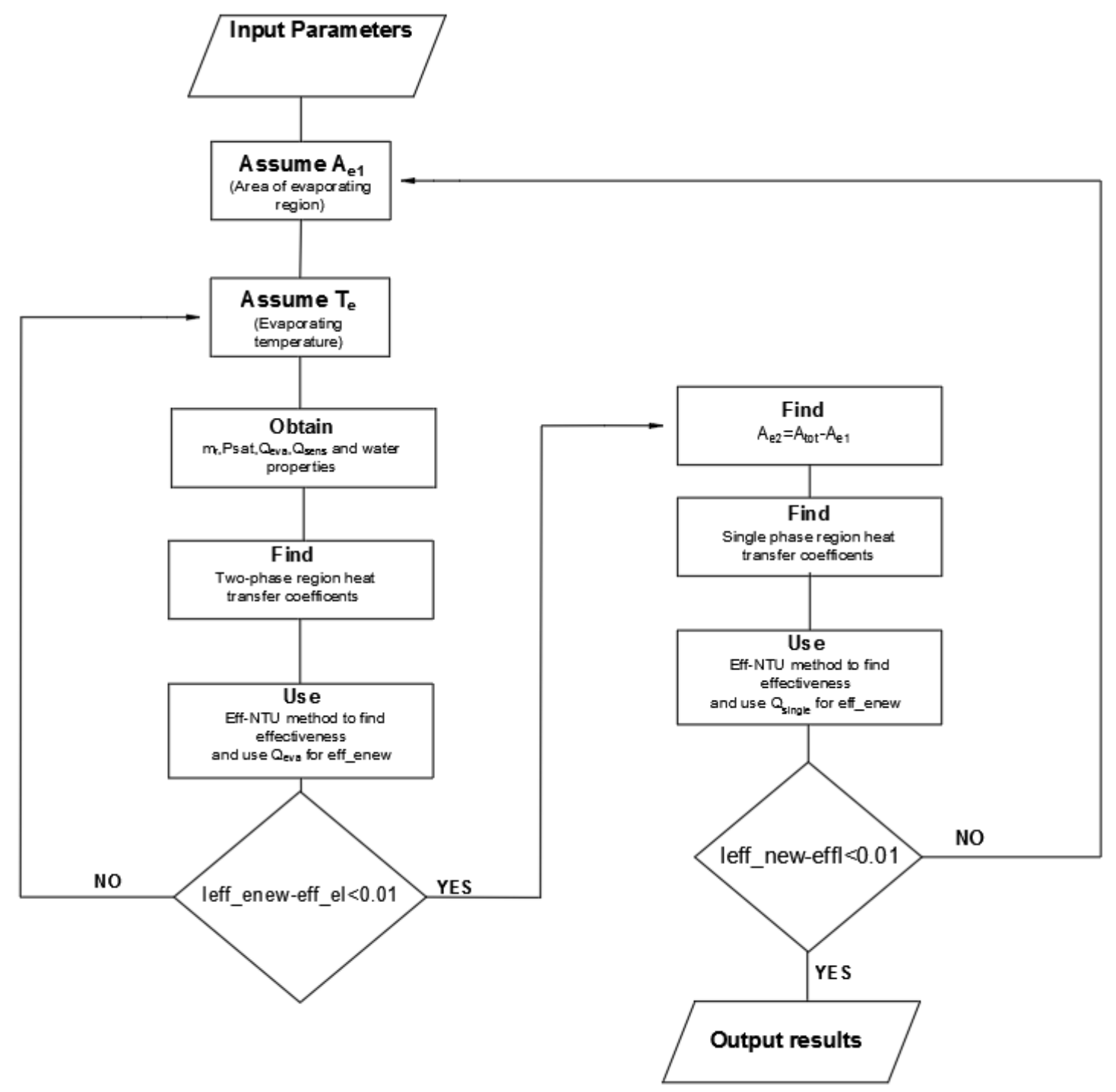

Fig. 9. Flow chart of off-design sliding pressure operation

\section{Results and discussions}

368 In the analysis, Engineering Equation Solver (EES) was used for obtaining the thermal 369 properties of the fluids. Regarding the following methodology of the transient states, the 370 initial temperatures in all subsystems with the exception of node temperatures in the tank, 371 have been set as equal to the ambient temperature. The equations given in Section 4.2 are 372 used in the developed program which is written in the software MATLAB. The differential 373 items in the storage tank modelling are discretized according to Eq. (25). This method solves 374 the quasi-steady problem in every time step and time interval is selected as 1 minute. In every 
time step, the produced work output, mass flow rates, fluid temperatures and available solar energy are calculated to assess the performance.

$$
\frac{\partial T_{s t}}{\partial t}=\frac{T_{s t}^{t+\Delta t}-T_{s t}^{t}}{\Delta t}
$$

\subsection{Design conditions of ORC}

In order to evaluate the system performance, firstly, design conditions need to be determined. Since condensing temperature depends on the ambient temperature in air cooled condenser, the ambient air temperature has an influence on the design conditions selection. Fig. 10 shows hourly ambient air temperature variation during a typical day in June in Istanbul. The ambient temperature has a slight variation during the day and mean temperature is around $20^{\circ} \mathrm{C}$. Therefore, the condensing temperature is selected as $30^{\circ} \mathrm{C}$. According to the specifications of the selected expander model with constant condensing temperature, the ORC behaviour, by varying evaporating temperature is presented in Fig. 11. Since the heat storage unit is a finite source, it is important to select the matched requirements according to Fig. 3 as a design point for avoiding excessive consumption of this finite source.

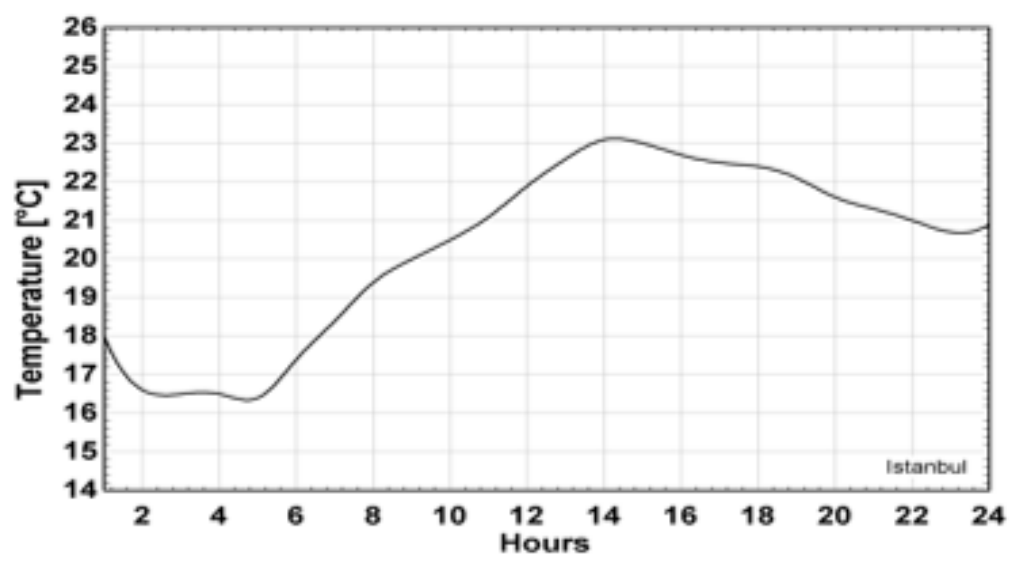

Fig. 10. Ambient temperature variation profile in Istanbul

After selecting the design condensation temperature of $30^{\circ} \mathrm{C}$, the design evaporation temperature should be corresponding to the built-in pressure ratio. However, the electricity demand needs to be considered for the peak period so the expander needs to operate at higher pressure ratio. Due to characteristic of the scroll expander, operation at higher pressure ratio 
has a slightly lower performance than operation at built-in ratio. It can be acceptable because peak period covers only $30 \%$ of the day, at the rest of the day, the expander operates with high performance. To meet the electricity demand for twelve dwellings at early night period, the expander speed is selected as $2500 \mathrm{rpm}$ and evaporating temperature as $96{ }^{\circ} \mathrm{C}$. As a result of these selections, work output and extracted heat from the water tank are expected to be 9.3 $\mathrm{kW}$ and $103.2 \mathrm{~kW}$, respectively. Given these conditions the evaporator needs to be dimensioned to predict the performance in all day simulation which refers to off-design conditions. The temperature of the water tank will go down by time, especially at night, and as a result the heat source temperature will not be constant. The heat exchanger has been designed using Eqs. (21)-(24) on which Fig. 12 has been based. It shows total length of the evaporator is dependent upon design inlet temperature and this length increases with lowering of the temperature. It should, however, be noted that these plots are drawn for $96{ }^{\circ} \mathrm{C}$ of evaporating temperature and when water inlet and evaporating temperatures approach, the required length of the heat exchanger will normally increase. It is expected that the heat source temperature which is the water tank temperature is around $130-100{ }^{\circ} \mathrm{C}$ during operating times, thus, water inlet temperature is selected as $110^{\circ} \mathrm{C}$ for design conditions.
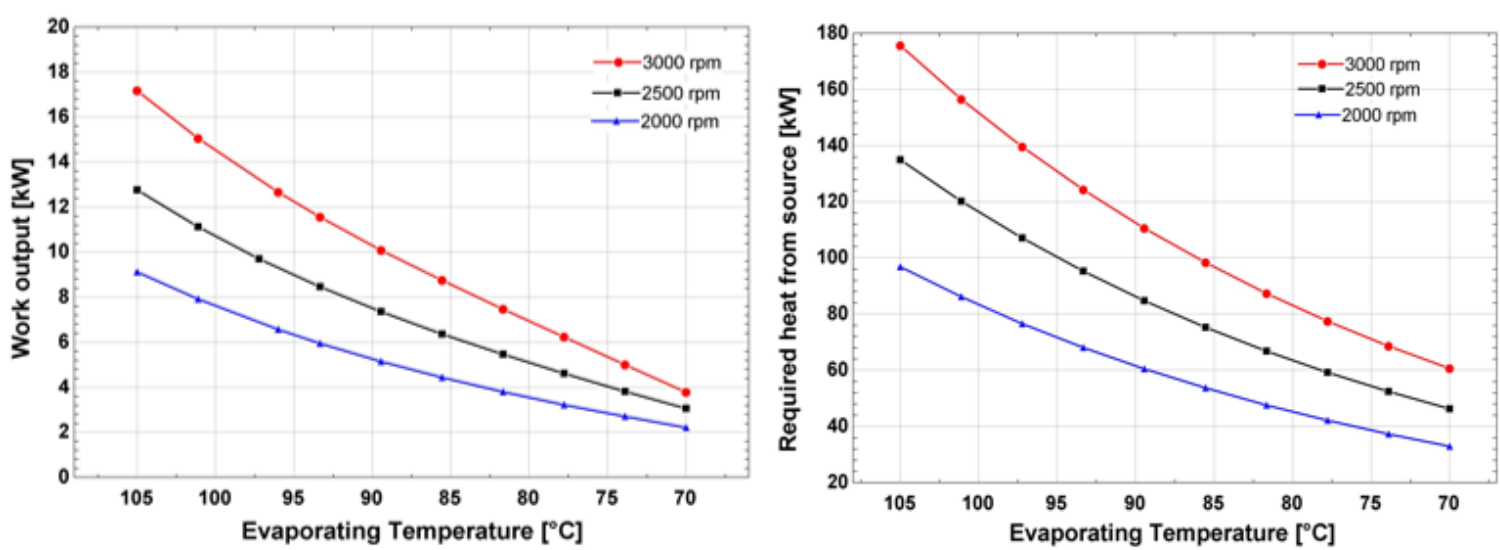

Fig. 11. Effect of evaporating temperature on work output and required heat for evaporation

The other parameter affecting the evaporator length is the mass flow rate of the water. A higher mass flow rate has the positive effect of shrinking the dimensions. However, it should be considered that higher mass flow rates can destroy the thermocline in the water storage tank. Therefore, water mass flow rate is selected as $2 \mathrm{~kg} / \mathrm{s}$ as a design parameter which leads to an evaporator of $51 \mathrm{~m}$. The effect of water mass flow rate on the system performance will 
be discussed in detail in a later section. Selected design parameters are summarised in Table 2.

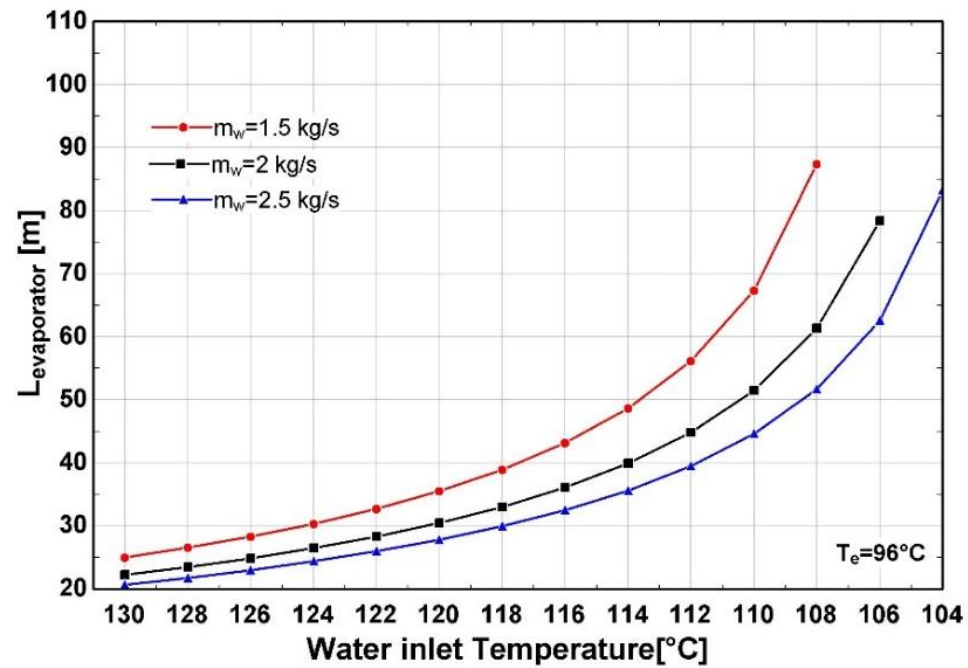

Fig. 12. Variation of the design length of the evaporator with water inlet temperature

Table 2. Selected design conditions

\begin{tabular}{|l|l|}
\hline Work output: $9.5 \mathrm{~kW}$ & Heat from source: $103.2 \mathrm{~kW}$ \\
\hline Evaporating temperature: $96^{\circ} \mathrm{C}$ & Expander speed: $2500 \mathrm{RPM}$ \\
\hline Condensing Temperature: $30^{\circ} \mathrm{C}$ & $\mathrm{m}_{\mathrm{w}}: 2 \mathrm{~kg} / \mathrm{s}$ \\
\hline Water inlet Temperature: $110^{\circ} \mathrm{C}$ & Evaporator length: $51 \mathrm{~m}$ \\
\hline Evaporator water side, $\mathrm{d}_{\mathrm{o}}: 0.3 \mathrm{~m}$ & Evaporator refrigerant side, $\mathrm{d}_{\mathrm{i}}: 0.012 \mathrm{~m}$ \\
\hline
\end{tabular}

\subsection{Off-design conditions}

Before simulating the whole system, the reaction of the heat exchangers when the system operates at off-design conditions is investigated. Firstly, the effect of water inlet temperature originating from top of the tank needs to be analysed. Furthermore, its effect also depends on mass flow rate. Fig. 13 shows the effect of the water inlet on evaporating temperature with various mass flow rates. And this analysis originates the controlling the power output methodology. Since the design conditions are $96^{\circ} \mathrm{C}$ and $110{ }^{\circ} \mathrm{C}$ of evaporating and water inlet temperatures, respectively, the heat exchanger has been dimensioned to satisfy these conditions. Sliding pressure operation control strategy is applied according to the flow chart in Fig. 9. This method is also applied in order to compare different water mass flow rates. It is observed that the evaporating temperature decreases when using lower water mass flow 
rate. The lower evaporating temperature yields both lower work output and lower extracted heat from the finite source. Fig. 14 shows the effect of the water inlet temperature on work output and ORC thermal efficiency. The ORC thermal efficiency has an important influence on the system metrics and as such, should be considered in the off-design performance. However, in this case, conservation of stored heat is important for early night period operation. A mass flow rate of $2 \mathrm{~kg} / \mathrm{s}$ has a higher work output and efficiency but using this flow results in more extracted heat from the source. Therefore, a mass flow rate of $0.5 \mathrm{~kg} / \mathrm{s}$ can be selected for day time and late night periods. It is seen from Fig. 14 that $0.5 \mathrm{~kg} / \mathrm{s}$ mass flow rate is proper to fulfil the demand when the inlet temperature is between $120^{\circ} \mathrm{C}$ and $105^{\circ} \mathrm{C}$.

449

450

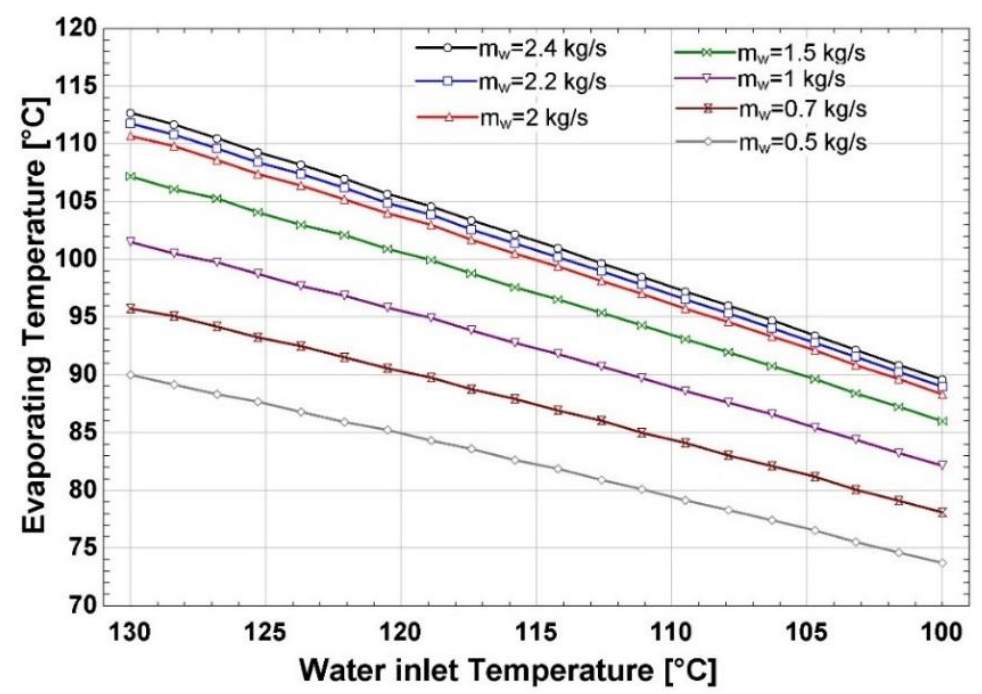

Fig. 13. Effect of water inlet temperature on evaporating temperature at different water mass flow rates.

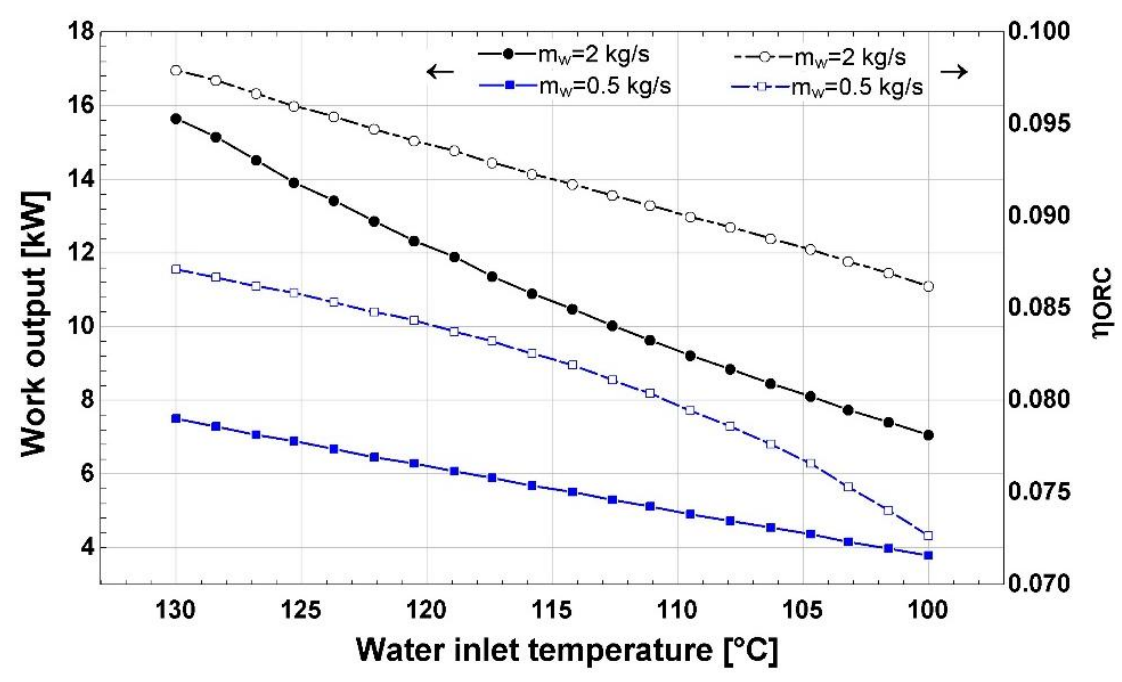


Fig. 14. Effect of water inlet temperature on work output and thermal ORC efficiency for

$$
\mathrm{m}_{\mathrm{w}}=2 \mathrm{~kg} / \mathrm{s} \text { and } \mathrm{m}_{\mathrm{w}}=0.5 \mathrm{~kg} / \mathrm{s}
$$

\subsection{Daily performance simulations}

In order to provide a performance assessment of the system, solar collector array and heat storage dimensions needs to be determined. The system is simulated for a clear day, relatively good solar irradiance but shorter day time which is presented in Fig. 15. The present system is analysed for a small community level application; it is chosen for twelve dwellings, so the area of solar collectors can be selected between $400 \mathrm{~m}^{2}$ and $600 \mathrm{~m}^{2}$. To observe good results $550 \mathrm{~m}^{2}$ is chosen, which equates to 300 collectors. Electricity demand reaches peak level in early night period and this peak demand claims approximately $10 \mathrm{~kW}$ output for 7 hours. Therefore, the system requires quite a large heat storage unit. According to a preliminarily assessment of the system, pressurized water tank volume should be higher than $70 \mathrm{~m}^{3}$. Since thermocline phenomena is considered in the present model, dimensions of the pressurized tank have an influence on the performance. Whilst thermocline is affected by many factors, this study only considers the one-dimensional temperature distribution model. The storage tank is selected as a cylinder with a diameter of 4 meter and height of 7 meter.

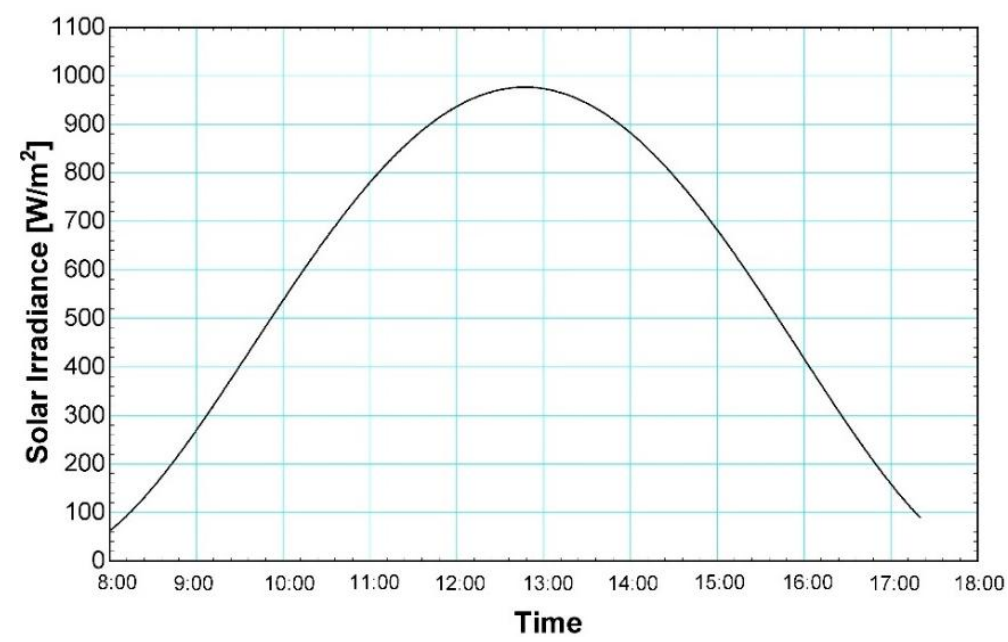

Fig. 15. Irradiance profile during a selected day

The system operation is based on the following strategy: day time period starts at 08:00, the collector pump runs and solar heat is stored in the tank, meanwhile the ORC produces electricity. Collector water mass flow rate is selected as $0.02 \mathrm{~kg} / \mathrm{s}$ per collector and is taken from the data sheet and the total mass flow rate poured into the tank is determined by the 
number of collectors. The ORC side water mass flow rate is chosen as $0.5 \mathrm{~kg} / \mathrm{s}$ to match electricity demand in the designed heat exchanger. Moreover, this prevents excessive use of the heat source. Day time period ends at 17:15 when solar irradiance is not sufficient and peak demand period starts. This period covers the main target of the study and ends at 24:00. Only ORC works and water mass flow rate are set at $2.4 \mathrm{~kg} / \mathrm{s}$ to satisfy the excessive demand by reaching higher evaporation temperature. The last period is late night period from 24:00 to 08:00. During this period, the water mass flow rate is switched to $0.5 \mathrm{~kg} / \mathrm{s}$ again as production of a high amount of electricity is not required. According to Fig. 13 and Fig. 14, it is expected that the tank temperature, especially the first node temperature, should be higher than $100^{\circ} \mathrm{C}$ both to provide the required production and to avoid low expander performance. Otherwise, the performance of the expander will be degraded significantly, as shown by the characteristic curve in Fig. 6. Therefore, initial tank temperature is selected as $100^{\circ} \mathrm{C}$ for simulations. One of the important aspect is selection of on-off criterion. To provide operation at the same conditions for other days the stop criterion has to be defined. The late night period production can be dispensable to conserve the stored heat in the tank for next day. It is found that when stop criterion is assigned as a condition in simulation it produces good results. Middle node of the tank, fifth node, is selected as stop consideration. When the temperature of the middle node reaches the initial condition, the working fluid pump is shut off and the tank is subjected to static mode only cooling until 08:00.

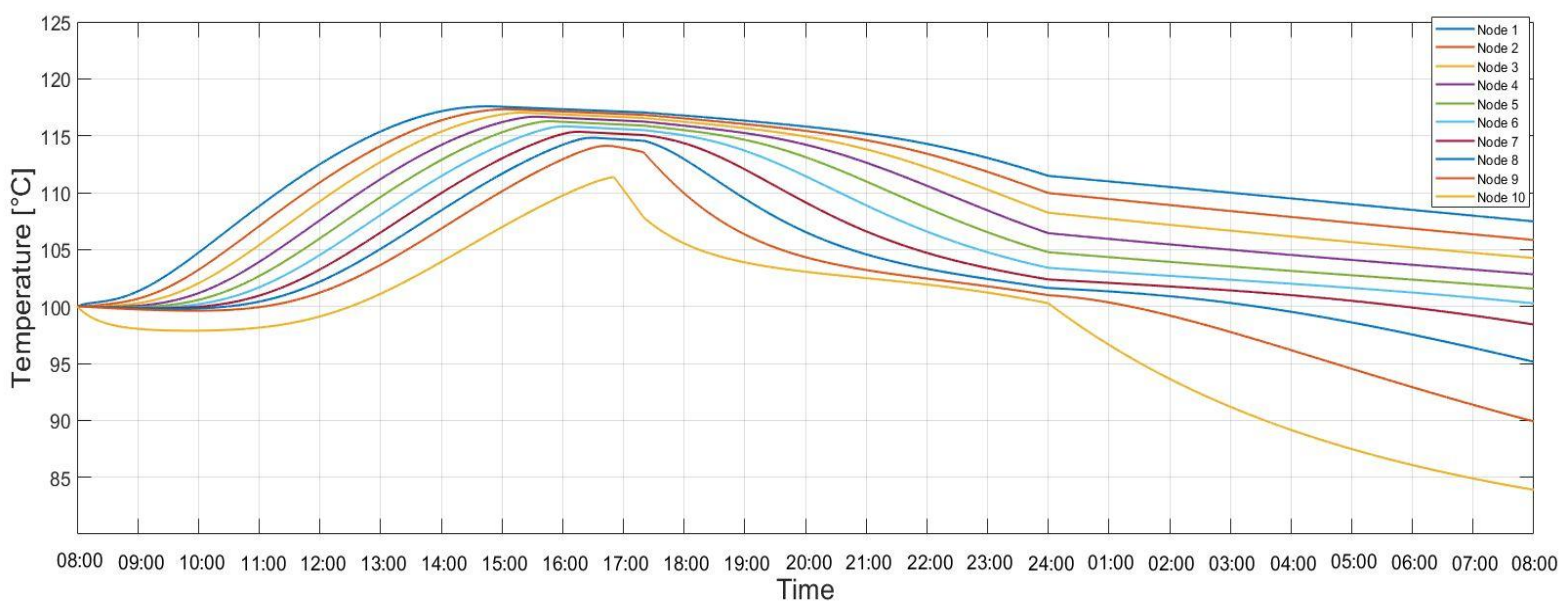

Fig. 16. Temperature distribution in the tank during first simulation 
502

503

504

505

506

507

508

509

510

511

512

513

514

515

516

517

518

519

520

521

522

523

524

One of the most important issues for the daily simulation is the selection of the initial temperature in the tank. According to previous sections, it can be concluded that temperature levels have an influence on the work output. Since selecting a proper initial tank temperature is significant for the results, it is required to eliminate this uncertain situation. Otherwise, it results in over-or underestimation of the work output.

In order to determine the reasonable initial condition, a number of simulations need to be conducted until initial and final temperatures reaching a stable level in the simulation. After finishing the first simulation, the second simulation's initial conditions are selected as the previous one's final temperatures. This iteration continues until the initial temperatures are matched with the final temperatures. Normally, the temperature gradient in the water tank is not the same at all levels; however, as a starting point, it is assumed that the initial temperature is $100^{\circ} \mathrm{C}$ for all nodes. After applying the control strategy described in the previous sections, Fig. 16 is plotted and it shows temperature distribution in the tank during the first 24 hours, and Fig. 17 shows work output results for the first 24 hours. Although the first node temperature is higher than in the early night period between 11:00 and 17:00, produced work is quite lower because of controlling of the evaporation temperature by mass flow rate. $0.5 \mathrm{~kg} / \mathrm{s}$ mass flow rate is used in day time and late night periods, whereas $2.4 \mathrm{~kg} / \mathrm{s}$ mass flow rate is used in early night period in all simulations. It is also shown that work generation is not ended for this day because the fifth node temperature does not reach the initial temperature and stop criterion can not be activated.

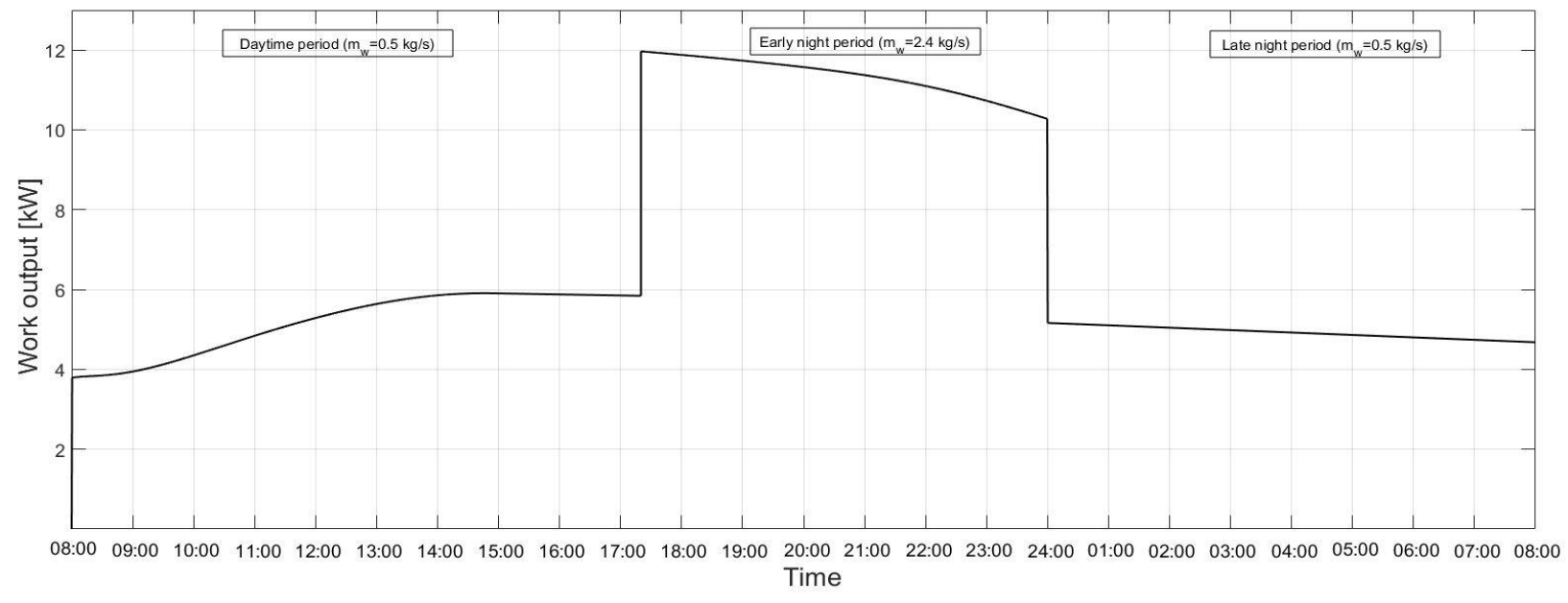

Fig. 17. Produced work during first simulation 
526 According to temperature distribution, it is observed that the last node temperature has a 527 different trend compared to other nodes. The reason can be explained with the temperature of 528 the water outlet from the evaporator which is discharged into the last node of the tank. This 529 colder fluid decreases the last node's temperature. However, its influence is quite insufficient 530 to the other nodes because it has a very low mass flow rate compared to the tank volume. In 531 the early night period, water mass flow rate is increased, which leads to an increase in the temperature of the water outlet from the evaporator. As a result of these, the degree of thermocline in the tank decreases. However, it is increased again by the lower flow rate in the late night period.

535 Fig. 16 and Fig. 17 show the first simulation results which are based on the assumption of the 536 same initial temperatures for all nodes in the tank. Using final temperatures as the next 537 simulation's initials, eight simulations have been conducted and temperature variations of the 538 initial temperatures are given in Fig. 18. By the $8^{\text {th }}$ simulation, temperatures become a stable 539 level, which means inlet and final temperatures are same. It can be said that all of the useful 540 solar heat charged to the tank are used for driving the ORC and the rest are transferred to the 541 ambient as heat losses. To explain in more detailed, Fig. 19 is plotted. It shows power outputs 542 in certain simulations. It can be seen that the cumulative work outputs are stabilized by the $8^{\text {th }}$ 543 simulation. It is likely because the $8^{\text {th }}$ simulation is more realistic for the selected typical day 544 so it is chosen as a reference day of the present study. In the third simulation, work output 545 falls dramatically, which can be explained by the assigned stop criterion. In that simulation, 546 the stop criterion is activated because temperature of the middle node falls to $100{ }^{\circ} \mathrm{C}$ at and 547 the work generation is interrupted to conserve the stored heat in the tank. It is seen that stored 548 heat from the third simulation is consumed in the fourth simulation and meets the demanded 549 electricity. It can be predicted that using a stop criterion, the system can balance itself for the 550 following simulations with fluctuated during late night period production. 


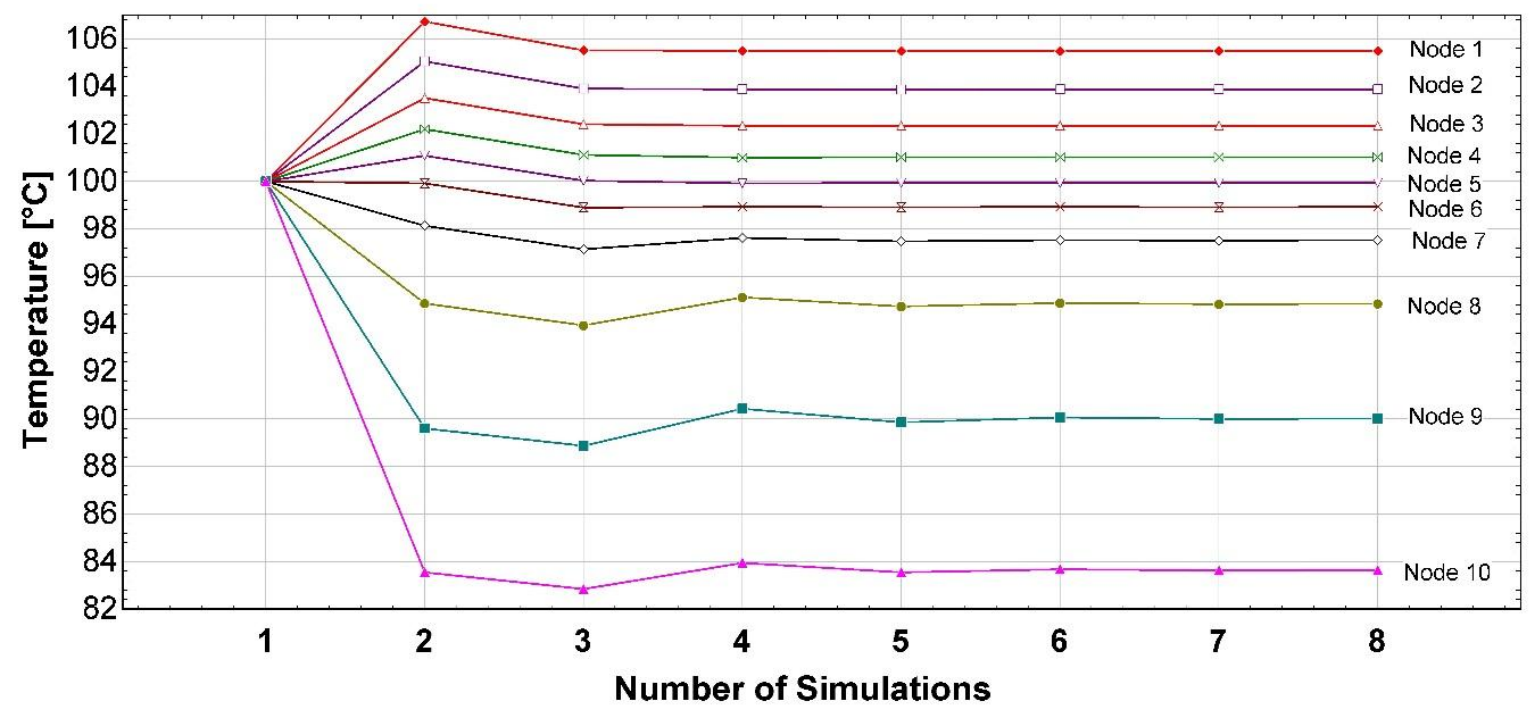

552 Fig. 18 Variations of initial temperature with the number of repetitive simulations for the given conditions

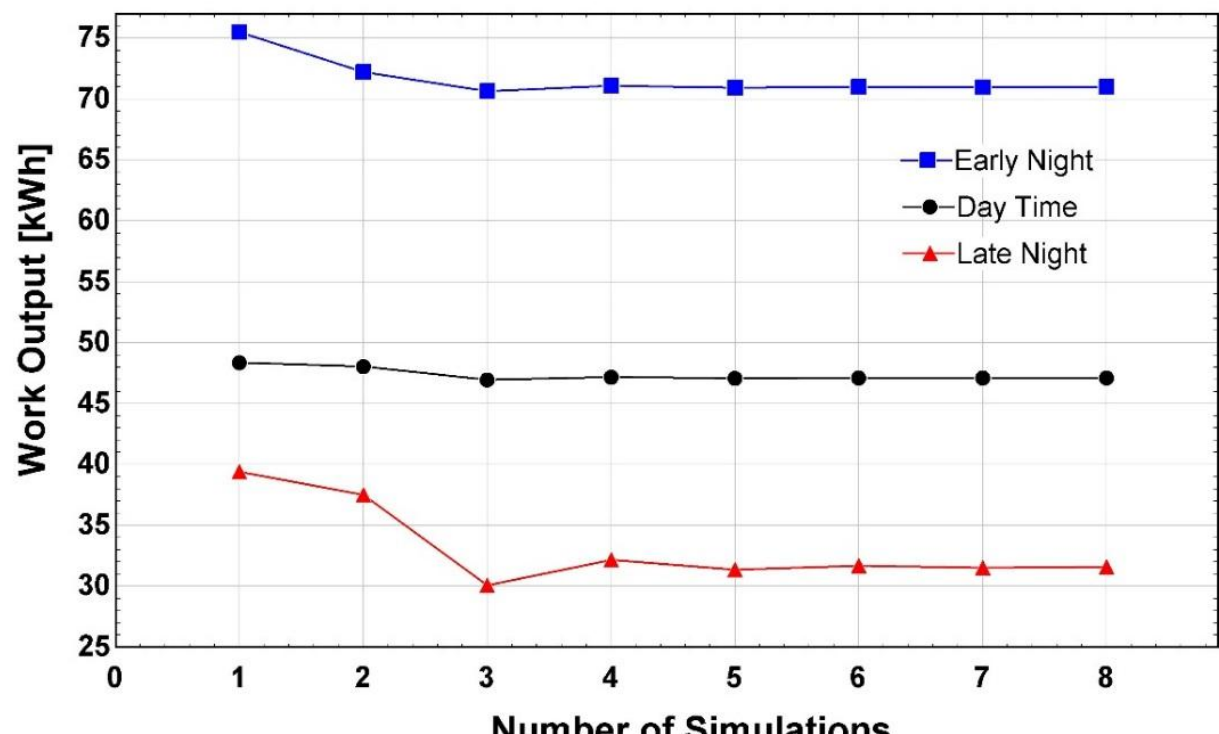

Fig. 19 Variation of work output with number of repetitive simulations

557 After determination of the initial temperatures, the system is ready for the investigation. Fig.

55820 shows the temperature distribution in the tank in hours. An interesting trend is observed 559 between 08:00 and 10:45. Although collector output is discharged into the first node, during 560 the first half hour this only affects the last node. Later, other nodes are affected and finally, it 561 gets mixed with the first node at 10:45. The reason for this trend is density difference. At the 
beginning, collector outlet temperature is only matched with the last node, however, later its temperature increases and systems operate as usual. The same phenomenon can be seen between 15:00 and 17:00 for all simulations.

The rest of the day has a similar trend with the Fig 16. The only difference is the period between 07:00 am and 08:00 am. During the last one hour, the system is switched to the static mode. It means the tank is only subjected to heat loss to the ambient.

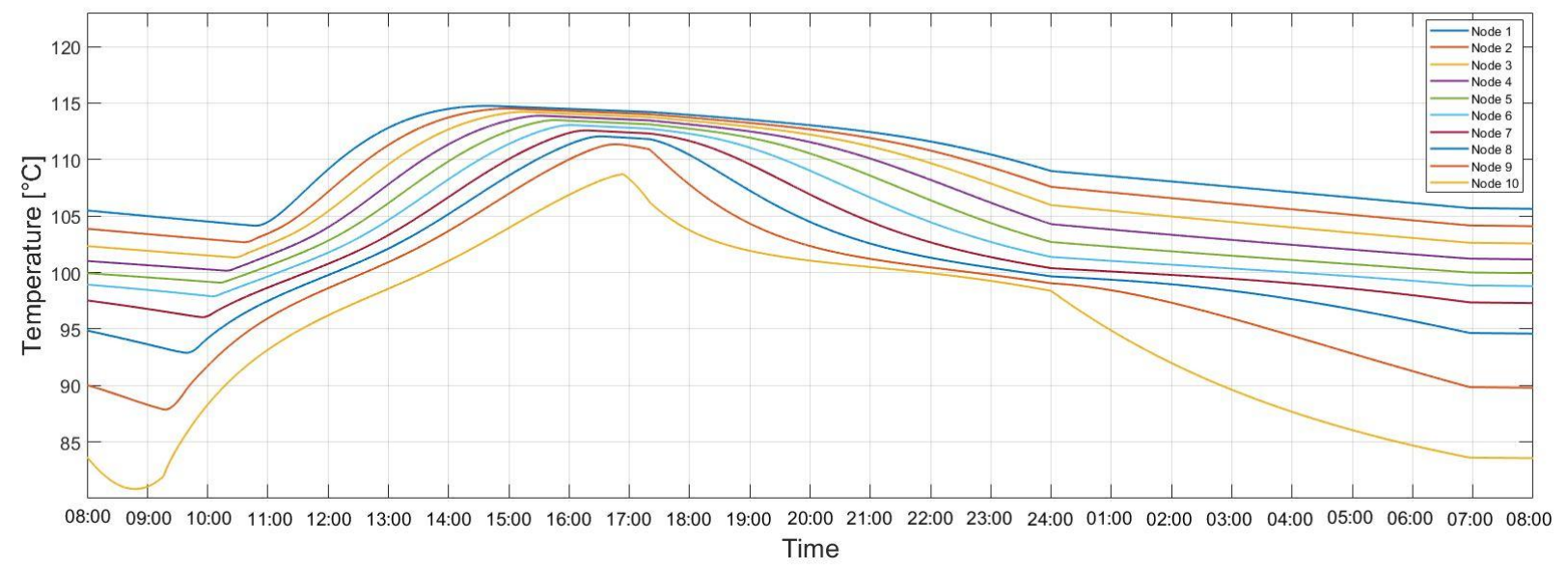

Fig. 20. Temperature distribution in the tank during 24 hours

Fig. 21 shows the work output of the system during 24 hours. The trend is quite similar with the Fig. 17 but during the first two hours, the production is higher and more stable compared to the Fig. 17. One of the reasons is the temperature difference. Previously, all temperatures were assumed as $100^{\circ} \mathrm{C}$. However, the first node temperature is determined as nearly $105^{\circ} \mathrm{C}$, which results in a higher work output. Also, stable generation comes from the steady first node temperature which is already explained in the Fig. 20. Moreover, it can be seen that work production is interrupted at 07:00 am because temperature of the middle node falls to $100{ }^{\circ} \mathrm{C}$. The stop criterion is activated at that time, the work generation is interrupted to conserve the stored heat in the tank. 
581

582

583

584 Fig. 22 shows variation of the collected useful heat from the solar collectors, rejected heat for

Fig. 21. Work output of the ORC during 24 hours the ORC and heat loss to the ambient by time. The heat loss varies between $7.15 \mathrm{~kW}$ and 8.22

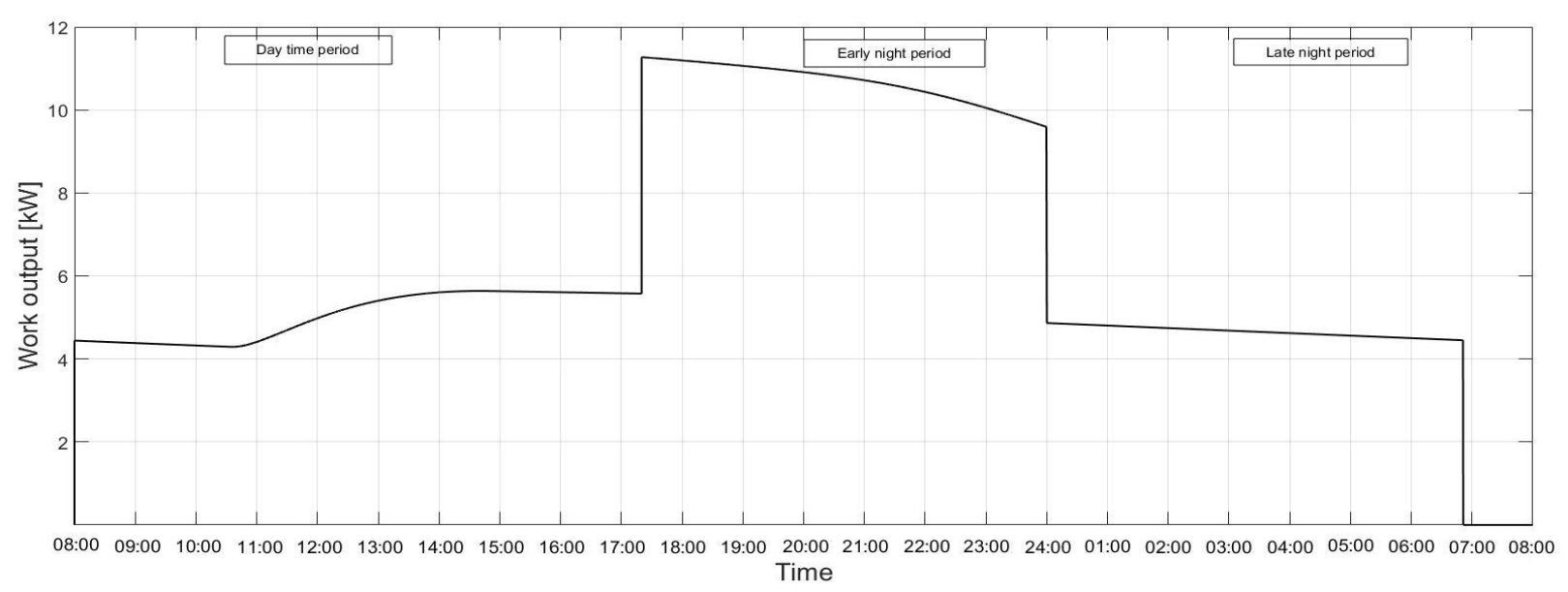
$\mathrm{kW}$. These values are quite low compared to amount of collected heat. Evacuated flat plate collector's efficiency reaches maximum value of 0.68 during the operation. The amount of collected useful heat peaks at 12:40 and about $367 \mathrm{~kW}$. The consumed heat for driving the ORC varies in different periods. During the day time period, it increases because water temperature of the first node is getting higher with higher solar irradiance. Then, it falls slightly as first node temperature is decreasing. During the early night period, evaporating temperature is increased. As a result of this increment, the consumed heat increases. In the late night period, the evaporating temperature is controlled for the purpose of decreasing it again, and it yields to lower heat ejection from the water tank. Fig. 22 also shows that all the useful collected energy is discharged during the simulation. This result makes the study more accurate because it eliminate the stored or excessive use of the energy in the tank. The initial temperatures has been chosen properly to avoid over-or underestimation of the work output for given typical conditions. 


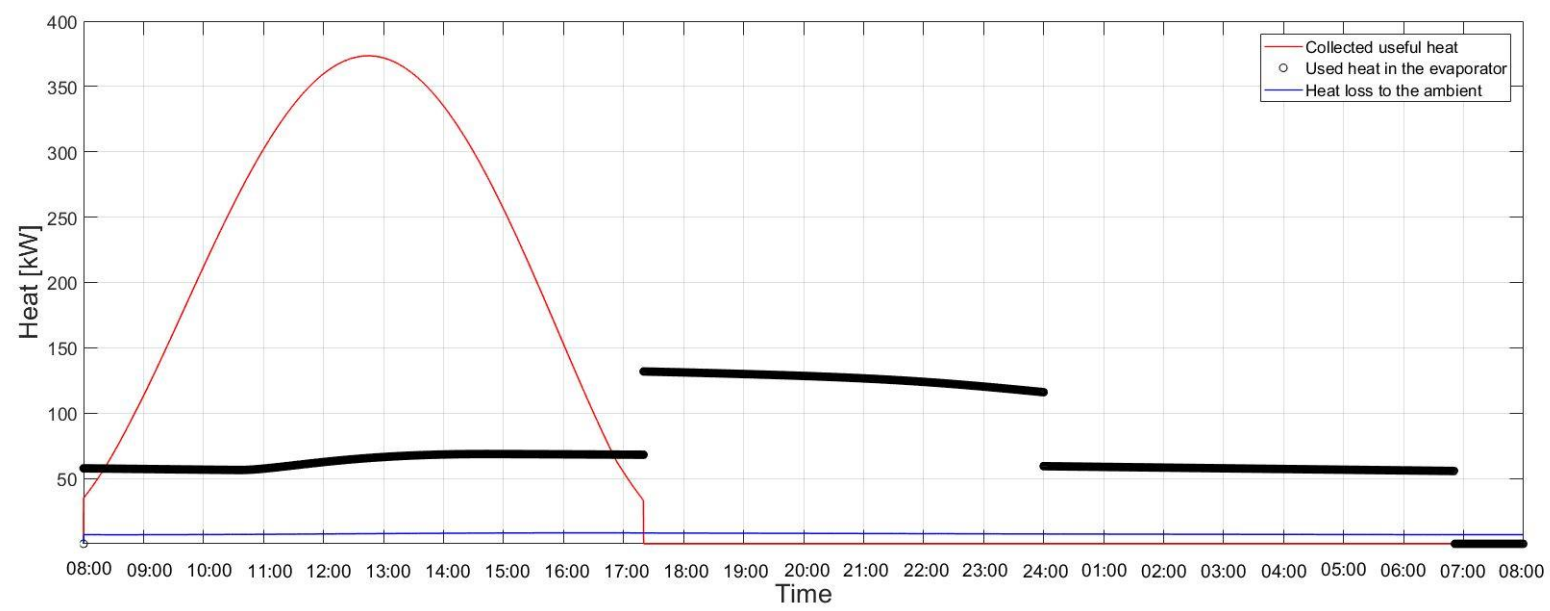

601

Fig. 22. All heat to which the tank exposed

602

603 To evaluate the off-design performance of the system, performance of the expander during 604 the second day has been analysed and it is shown in Fig. 23a. During the daytime and late night periods, the isentropic efficiency of the expander varies slightly. Referring to the Fig. 6, since expander operation pressure difference range at these periods are close to expander design pressure ratio (low evaporating temperature despite higher water temperature during these periods), its performance is higher. However, during the peak period, it falls below 0.63 because evaporating temperature is forced to increase by the present model for controlling the expander output. According to off-design performance of the expander, this control strategy looks proper because peak period takes only 7 of 24 hours, remaining hours system operates at the very close range of the expander's maximum performance.

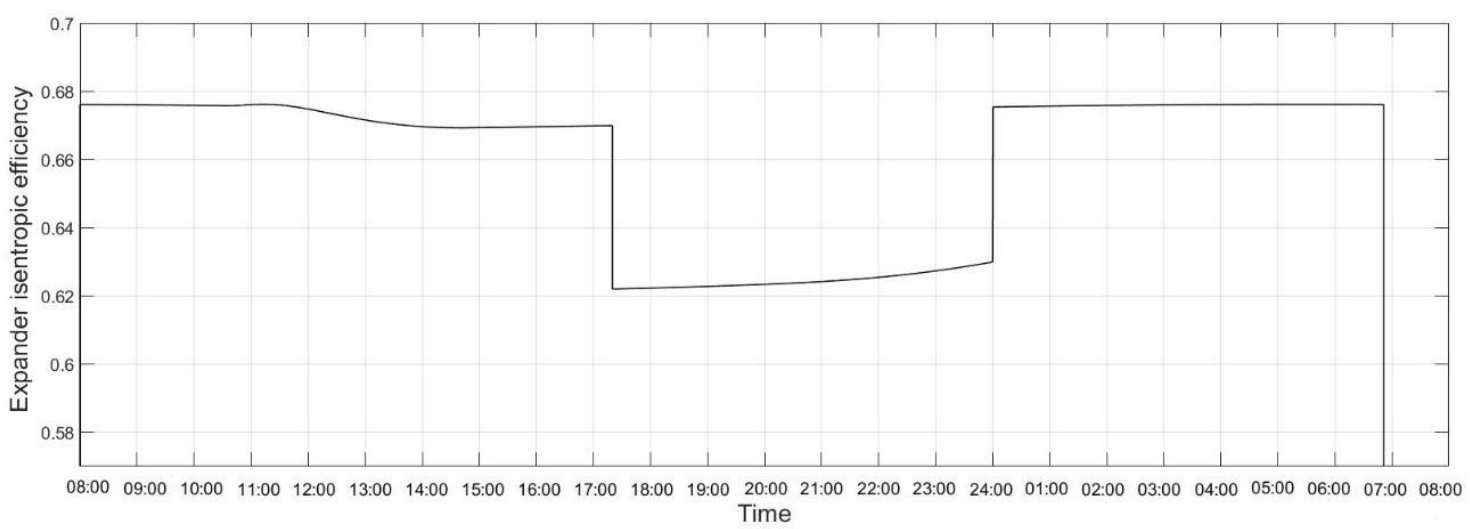




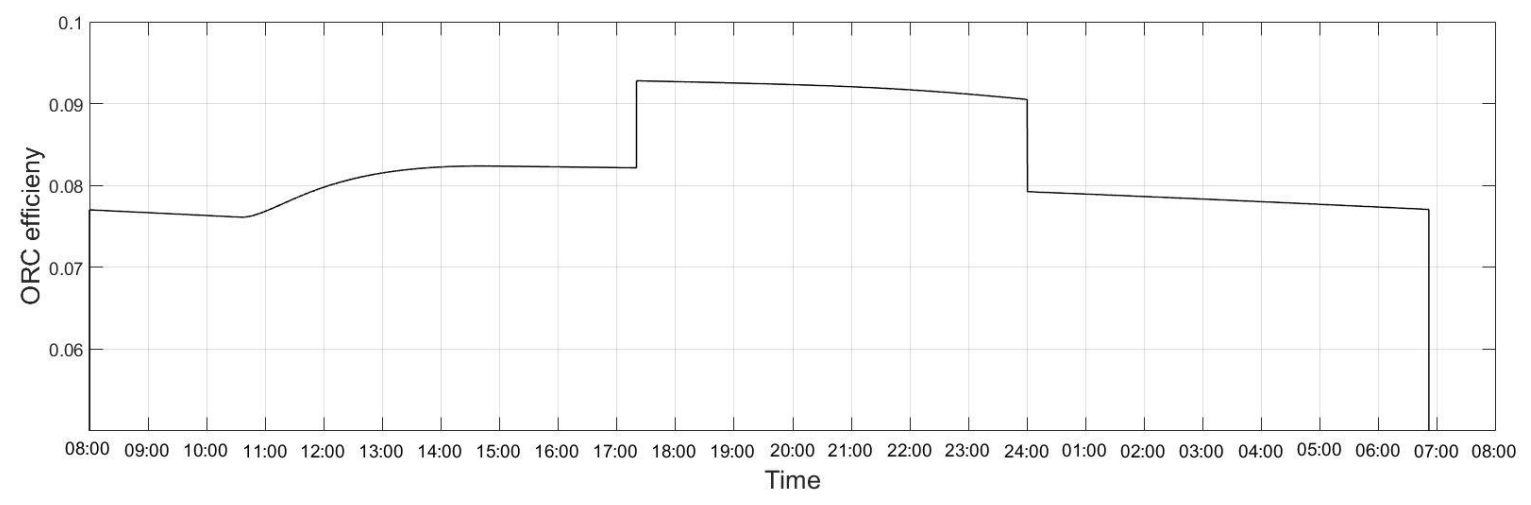

b)

Fig. 23. a) Expander isentropic efficiency. b) ORC efficiency during 24 hours

ORC efficiency is also useful metric for evaluation of the system performance. It is related with some parameters but in the present study, main factor is evaporating temperature which is higher during the peak time period. Fig. 23b shows the ORC efficiency during second day. In the other periods the evaporating temperature is forced to decrease by the present model. The main purpose is to avoid using the heat source excessively and of course to meet the demand. The efficiency variation is observed between 0.076 and 0.092 .

\section{Conclusions}

In this study, a research into off-design performance of a solar ORC system integrated with a compressed water heat storage unit has been conducted based on fulfilment of the end user variable demand during the day from the point of view of control strategies. The analysed system combining the evacuated flat plate collector and the heat storage unit to provide all day power generation offers promising results. The heat storage unit has been analysed using a one-dimensional temperature distribution model to represent the thermocline phenomena. However, it is known that lots of parameters affect the thermocline, so a more complex model may result in more accurate findings. Nonetheless, there is no doubt that this simplified stratification model gives more realistic results than the fully mixed uniform model. Moreover, a proper initial tank temperature distribution has been determined by repeating simulation several times in order to conduct a proper daily simulation analysis under given conditions. 
640 The present paper has shown that power output can be adjusted by controlling the mass flow 641 rate of the circulation water and it is possible to meet electricity demand at night. The ORC 642 has been successfully simulated at variable heat source temperature by use of sliding pressure 643 control strategy. Throughout the simulation, the power output was ranged from 4.3 to $5.7 \mathrm{~kW}$ 644 in the daytime, $9-11.2 \mathrm{~kW}$ at early night and $4.7-4.3 \mathrm{~kW}$ at late night via adjustment of water 645 mass flow rate in the evaporator of ORC. And there is no significant degradation in expander 646 performance during the adjustment.

647

648 Acknowledgements

649 The authors would like to thank the European Commission for the Marie Curie Fellowship 650 grant (H2020-MSCA-IF-2015-703746).

\section{Nomenclature}

A Area, $\mathrm{m}^{2}$

$c_{1} \quad$ Heat loss term, $\mathrm{W} \mathrm{m}{ }^{-2} \mathrm{~K}^{-1}$

$c_{2} \quad$ Heat loss term, $\mathrm{W} \mathrm{m}^{-2} \mathrm{~K}^{-2}$

$c_{p} \quad$ Specific heat, $\mathrm{J} \mathrm{kg}^{-1}$

$d_{s t} \quad$ Water tank diameter, $\mathrm{m}$

$\Delta k \quad$ De-stratification conductivity, $\mathrm{W} \mathrm{m}^{-1} \mathrm{~K}^{-1}$

$G$ Solar irradiance, $\mathrm{W} \mathrm{m}^{-2}$

$h \quad$ Heat transfer coefficient, $\mathrm{W} \mathrm{m}^{-2} \mathrm{~K}^{-1}$

$\mathrm{k}$ Thermal conductivity, $\mathrm{W} \mathrm{m}^{-1} \mathrm{~K}^{-1}$

$K_{\theta} \quad$ Incident angle modifier

L Water tank height, $m$

$\dot{m}$ Mass flow rate, $\mathrm{kg} \mathrm{s}^{-1}$

$M \quad$ Mass, $\mathrm{kg}$

$\mathrm{N}$ Total node number

Pr Prandtl number

Re Reynolds number

$r_{p} \quad$ Pressure ratio

\section{Subscripts}

$\begin{array}{cl}\text { am } & \text { Ambient } \\ \mathrm{b} & \text { boiling } \\ \mathrm{col} & \text { Collector } \\ \mathrm{cw} & \text { Water in collector } \\ e & \text { Evaporating } \\ \mathrm{ex} & \text { Exhaust } \\ \mathrm{e}_{1} & \text { Evaporating region } \\ \mathrm{e}_{2} & \text { Single phase region } \\ m e & \text { Mechanical } \\ r & \text { Refrigerant } \\ s t & \text { Storage } \\ \mathrm{stN} & \text { Last node } \\ v & \text { Vapour } \\ w & \text { Water } \\ w o & \text { Water out from evaporator } \\ s u & \text { Supply }\end{array}$


$\bar{T} \quad$ Mean temperature, ${ }^{\circ} \mathrm{C}$

$T$ Temperature, ${ }^{\circ} \mathrm{C}$

$U \quad$ Overall heat transfer coefficient, $\mathrm{W} \mathrm{m}^{-2} \mathrm{~K}^{-1}$

$\dot{V}_{S} \quad$ Swept volume, $\mathrm{m}^{3} \mathrm{~s}^{-1}$

$\mathrm{X} \quad$ Vapour quality

$X_{p} \quad$ Pump capacity fraction $t \quad$ Tank

\section{Greek letters}

$\begin{array}{ll}\eta & \text { Efficiency } \\ \phi & \text { Filling factor } \\ \rho & \text { Density, } \mathrm{kg} \mathrm{m}^{-3}\end{array}$

\section{References}

[1] A. Modi, F. Buhler, J. G. Andreasen, and F. Haglind, "A review of solar energy based heat and power generation systems," Renew. Sustain. Energy Rev., vol. 67, pp. 10471064, 2017.

[2] M. Muratori, M. C. Roberts, R. Sioshansi, V. Marano, and G. Rizzoni, "A highly resolved modeling technique to simulate residential power demand," Appl. Energy, vol. 107, pp. 465-473, 2013.

[3] J. L. Ramírez-Mendiola, P. Grünewald, and N. Eyre, "The diversity of residential electricity demand - A comparative analysis of metered and simulated data," Energy Build., vol. 151, pp. 121-131, 2017.

[4] M. Hayn, V. Bertsch, and W. Fichtner, "Electricity load profiles in Europe: The importance of household segmentation," Energy Res. Soc. Sci., vol. 3, no. C, pp. 30$45,2014$.

[5] J. Torriti, "The Risk of Residential Peak Electricity Demand: A Comparison of Five European Countries," Energies, vol. 10, no. 3, p. 385, 2017.

[6] J. Freeman, I. Guarracino, S. A. Kalogirou, and C. N. Markides, "A small-scale solar organic Rankine cycle combined heat and power system with integrated thermalenergy storage," Appl. Therm. Eng., vol. 127, pp. 1543-1554, 2017.

[7] D. P. Kaundinya, P. Balachandra, and N. H. Ravindranath, "Grid-connected versus stand-alone energy systems for decentralized power-A review of literature," Renew. Sustain. Energy Rev., vol. 13, no. 8, pp. 2041-2050, 2009.

[8] V. R. Patil, V. I. Biradar, R. Shreyas, P. Garg, M. S. Orosz, and N. C. Thirumalai, "Techno-economic comparison of solar organic Rankine cycle (ORC) and photovoltaic (PV) systems with energy storage," Renew. Energy, vol. 113, pp. 12501260, 2017.

[9] S. C. Yang, T. C. Hung, Y. Q. Feng, C. J. Wu, K. W. Wong, and K. C. Huang, "Experimental investigation on a $3 \mathrm{~kW}$ organic Rankine cycle for low-grade waste heat under different operation parameters," Appl. Therm. Eng., vol. 113, no. December 2015, pp. 756-764, 2017.

[10] J. Wang, Z. Yan, P. Zhao, and Y. Dai, "Off-design performance analysis of a solarpowered organic Rankine cycle," Energy Convers. Manag., vol. 80, pp. 150-157, 2014.

[11] R. Chacartegui, L. Vigna, J. A. Becerra, and V. Verda, "Analysis of two heat storage integrations for an Organic Rankine Cycle Parabolic trough solar power plant," Energy Convers. Manag., vol. 125, pp. 353-367, 2016. 
[12] C. Tzivanidis, E. Bellos, and K. A. Antonopoulos, "Energetic and financial investigation of a stand-alone solar-thermal Organic Rankine Cycle power plant," Energy Convers. Manag., vol. 126, pp. 421-433, 2016.

[13] X. D. Wang, L. Zhao, J. L. Wang, W. Z. Zhang, X. Z. Zhao, and W. Wu, "Performance evaluation of a low-temperature solar Rankine cycle system utilizing R245fa," Sol. Energy, vol. 84, no. 3, pp. 353-364, 2010.

[14] M. Wang, J. Wang, Y. Zhao, P. Zhao, and Y. Dai, "Thermodynamic analysis and optimization of a solar-driven regenerative organic Rankine cycle (ORC) based on flat-plate solar collectors," Appl. Therm. Eng., vol. 50, no. 1, pp. 816-825, 2013.

[15] A. Baccioli, M. Antonelli, and U. Desideri, "Dynamic modeling of a solar ORC with compound parabolic collectors: Annual production and comparison with steady-state simulation," Energy Convers. Manag., vol. 148, pp. 708-723, 2017.

[16] J. Z. Alvi, M. Imran, G. Pei, J. Li, G. Gao, and J. Alvi, "Thermodynamic comparison and dynamic simulation of direct and indirect solar organic Rankine cycle systems with PCM storage," Energy Procedia, vol. 129, pp. 716-723, 2017.

[17] S. Li, H. Ma, and W. Li, "Dynamic Performance Analysis of Solar Organic Rankine Cycle with Thermal Energy Storage," Appl. Therm. Eng., vol. 129, pp. 155-164, 2018.

[18] J. F. Feldhoff et al., "Comparative system analysis of direct steam generation and synthetic oil parabolic trough power plants with integrated thermal storage," Sol. Energy, vol. 86, no. 1, pp. 520-530, 2012.

[19] J. Li, P. Li, G. Gao, G. Pei, Y. Su, and J. Ji, “Thermodynamic and economic investigation of a screw expander-based direct steam generation solar cascade Rankine cycle system using water as thermal storage fluid," Appl. Energy, vol. 195, pp. 137$151,2017$.

[20] E. Bellos, C. Tzivanidis, and K. A. Antonopoulos, "Exergetic , energetic and financial evaluation of a solar driven absorption cooling system with various collector types," Appl. Therm. Eng., vol. 102, pp. 749-759, 2016.

[21] J. Li, J. Zeb, G. Pei, J. Ji, P. Li, and H. Fu, "Effect of working fluids on the performance of a novel direct vapor generation solar organic Rankine cycle system," Appl. Therm. Eng., vol. 98, pp. 786-797, 2016.

[22] J. Freeman, K. Hellgardt, and C. N. Markides, "Working fluid selection and electrical performance optimisation of a domestic solar-ORC combined heat and power system for year-round operation in the UK," Appl. Energy, vol. 186, pp. 291-303, 2017.

[23] S. Declaye, S. Quoilin, L. Guillaume, and V. Lemort, "Experimental study on an opendrive scroll expander integrated into an ORC ( Organic Rankine Cycle ) system with R245fa as working fl uid," Energy, vol. 55, pp. 173-183, 2013.

[24] D. Budisulistyo and S. Krumdieck, "A novel design methodology for waste heat recovery systems using organic Rankine cycle,” Energy Convers. Manag., vol. 142, pp. 1-12, 2017.

[25] V. Lemort, S. Declaye, and S. Quoilin, "Experimental characterization of a hermetic scroll expander for use in a micro-scale Rankine cycle," Proc. Inst. Mech. Eng. Part A J. Power Energy, vol. 226, no. 1, pp. 126-136, 2012. 
[26] J. Li, G. Pei, J. Ji, X. Bai, P. Li, and L. Xia, "Design of the ORC (organic Rankine cycle) condensation temperature with respect to the expander characteristics for domestic CHP (combined heat and power) applications," Energy, vol. 77, pp. 579$590,2014$.

[27] D. Hu, Y. Zheng, Y. Wu, S. Li, and Y. Dai, "Off-design performance comparison of an organic Rankine cycle under different control strategies," Appl. Energy, vol. 156, pp. 268-279, 2015.

[28] B.-R. Fu, S.-W. Hsu, Y.-R. Lee, J.-C. Hsieh, C.-M. Chang, and C.-H. Liu, "Effect of off-design heat source temperature on heat transfer characteristics and system performance of a 250-kW organic Rankine cycle system," Appl. Therm. Eng., vol. 70, no. 1, pp. 7-12, 2014.

[29] I. S. Kim, T. S. Kim, and J. J. Lee, "Off-design performance analysis of organic Rankine cycle using real operation data from a heat source plant," Energy Convers. Manag., vol. 133, pp. 284-291, 2017.

[30] F. Calise, M. D. D’Accadia, M. Vicidomini, and M. Scarpellino, "Design and simulation of a prototype of a small-scale solar CHP system based on evacuated flatplate solar collectors and Organic Rankine Cycle," Energy Convers. Manag., vol. 90, pp. 347-363, 2015.

[31] G. Li, "Sensible heat thermal storage energy and exergy performance evaluations," Renew. Sustain. Energy Rev., vol. 53, pp. 897-923, 2016.

[32] J. A. Duffie and W. A. Beckman, Solar Engineering of Thermal Processes. John Wiley, 2013.

[33] E. Bellos, C. Tzivanidis, C. Symeou, and K. A. Antonopoulos, "Energetic, exergetic and financial evaluation of a solar driven absorption chiller - A dynamic approach," Energy Convers. Manag., vol. 137, pp. 34-48, 2017.

[34] E. Bellos, M. G. Vrachopoulos, and C. Tzivanidis, "Energetic and exergetic investigation of a novel solar assisted mechanical compression refrigeration system," Energy Convers. Manag., vol. 147, pp. 1-18, 2017.

[35] E. Bellos, C. Tzivanidis, K. Moschos, and K. A. Antonopoulos, "Energetic and financial evaluation of solar assisted heat pump space heating systems," Energy Convers. Manag., vol. 120, pp. 306-319, 2016.

[36] J. Fan and S. Furbo, "Thermal stratification in a hot water tank established by heat loss from the tank," Sol. Energy, vol. 86, no. 11, pp. 3460-3469, 2012.

[37] C. A. Cruickshank and S. J. Harrison, "Heat loss characteristics for a typical solar domestic hot water storage," Energy Build., vol. 42, no. 10, pp. 1703-1710, 2010.

[38] P. Armstrong, D. Ager, I. Thompson, and M. Mcculloch, "Improving the energy storage capability of hot water tanks through wall material speci fi cation," Energy, vol. 78, pp. 128-140, 2014.

[39] B. J. Newton, "Modeling of Solar Storage Tanks," University of Wisconsin-Madison, 1995.

[40] S. Quoilin, R. Aumann, A. Grill, A. Schuster, and V. Lemort, "Dynamic modeling and optimal control strategy of waste heat recovery Organic Rankine Cycles," Appl. 
Energy, vol. 88, no. 6, pp. 2183-2190, 2011.

[41] D. Ziviani et al., "Optimizing the performance of small-scale organic Rankine cycle that utilizes a single-screw expander," Appl. Energy, vol. 189, pp. 416-432, 2017.

[42] S. Quoilin, V. Lemort, and J. Lebrun, "Experimental study and modeling of an Organic Rankine Cycle using scroll expander," Appl. Energy, vol. 87, no. 4, pp. 1260$1268,2010$.

[43] E. Rodriguez and B. Rasmussen, "A comparison of modeling paradigms for dynamic evaporator simulations with variable fluid phases," Appl. Therm. Eng., vol. 112, pp. 1326-1342, 2017.

[44] M. Yousefzadeh and E. Uzgoren, "Mass-conserving dynamic organic Rankine cycle model to investigate the link between mass distribution and system state," Energy, vol. 93, pp. 1128-1139, 2015.

[45] S. Unal, M. T. Erdinc, and C. Kutlu, "Optimal thermodynamic parameters of twophase ejector refrigeration system for buses," Appl. Therm. Eng., vol. 124, pp. 13541367, 2017.

[46] M. O. Bamgbopa and E. Uzgoren, "Quasi-dynamic model for an organic Rankine cycle," Energy Convers. Manag., vol. 72, pp. 117-124, 2013.

[47] Y. Cengel, Heat Transfer: A practical approach. McGraw-Hill 2003.

[48] L. Sun and K. Mishima, "An evaluation of prediction methods for saturated flow boiling heat transfer in mini-channels," Int. J. Heat Mass Transf., vol. 52, no. 23-24, pp. 5323-5329, 2009. 